\title{
Enigmatic Sebacinales
}

\author{
Franz Oberwinkler • Kai Riess • Robert Bauer • \\ Marc-André Selosse • Michael Weiß • \\ Sigisfredo Garnica • Alga Zuccaro
}

Received: 12 November 2012 /Revised: 6 December 2012 / Accepted: 11 December 2012 /Published online: 4 January 2013

(C) German Mycological Society and Springer-Verlag Berlin Heidelberg 2013

\begin{abstract}
A historical retrospect and a taxonomic update will deal with Sebacina s.l. and s.str., Craterocolla, Efibulobasidium, Serendipita, Tremellodendron, Tremelloscypha, Tremellostereum, and Piriformospora, the Sebacinaceae, and the Sebacinales. Phylogenetic hypotheses for the order and subordinal taxa are discussed, including environmental sequence taxa. The cryptic biodiversity in Sebacinales is extensive but mostly unresolved with respect to the species involved. Trophic stages are manifold in Sebacinales but restricted to plant dependencies. Most of the species grow endophytically or form various mycorrhizae, but Craterocolla and Efibulobasidium species appear to be saprobic. The sebacinalean mycorrhizal diversity is unparalleled: ectomycorrhizae, ericoid and orchid mycorrhizae are frequent, both in autotrophs and heterotrophs, as well as mycothalli with Jungermanniales. Mycorrhizal community structures are difficult to evaluate in Sebacinales because of the high percentage of environmental sequence taxa lacking further characteristics. Nutritional requirements and exchanges have been studied extensively in Piriformospora indica,
\end{abstract}

F. Oberwinkler $\cdot$ K. Riess $\cdot$ R. Bauer $\cdot$ S. Garnica $(\bowtie)$ Institut für Evolution und Ökologie, Evolutionäre Ökologie der Pflanzen, Universität Tübingen, Auf der Morgenstelle 1, 72076 Tübingen, Germany

e-mail: sigisfredo.garnica@uni-tuebingen.de

M.-A. Selosse

Centre d'Écologie Fonctionnelle et Évolutive (CNRS, UMR 5175), 1919 Route de Mende, 34293 Montpellier cedex 5, France

M. Weiß

Fachbereich Biologie, Universität Tübingen,

Auf der Morgenstelle 5,

72076 Tübingen, Germany

\section{A. Zuccaro}

Max-Planck-Institut für, terrestrische Mikrobiologie,

Karl-von-Frisch-Straße 10,

35043 Marburg, Germany suggesting future possibilities for agricultural applications. The genomes of this species and of Sebacina vermifera have been sequenced recently, thus opening new fields in studying and understanding functional and evolutionary aspects.

\section{History and taxonomy}

In 1871, the french mycologists Louis René and Charles Tulasne erected the genus Sebacina with the type species $S$. incrustans (Figs. 1a and 2c). They recognized that Corticium incrustans, described by Persoon in 1796, is phragmobasidiate in contrast to the holobasidiate Corticium species. The species prefers to grow on soil, encrusting litter and plant material on the ground. Also, fruiting on soil is typical for another common species in forests, S. epigaea (Fig. 1b), transferred by Bourdot and Galzin (1927) to Sebacina. Already in 1848, Berkley and Broome found the longitudinally septate, tremelloid basidia, and consequently described the thus far unknown species as Tremella epigaea. A species with a dimitic hyphal system was recognized by Oberwinkler (1963) and described as S. dimitica (Fig. 1c).

When studying inconspicuous corticioid Basidiomycetes, Oberwinkler (1964) found a Sebacina with scattered hyphae, which forms neither a basidiocarp nor a hymenial layer, and is therefore not visible to the naked eye. Because of its nematode-like basidiospores, the species was named $S$. vermifera (Figs. 1j and 21). Warcup and Talbot (1967) succeeded to isolate and cultivate a basidiomycetous fungus from orchid roots in South Australia. They found tremelloid basidia and vermiform basidiospores in culture, and consequently identified the isolate as $S$. vermifera. Roberts (1993) typified his newly introduced genus Serendipita with $S$. vermifera ss. Oberwinkler. Another inconspicuous species with efibulate hyphae, Sebacina allantoidea, has been described by Kirschner and Oberwinkler (2002). Additional taxa cannot be discussed here, because micromorphology is not documented sufficiently and molecular data are lacking. 


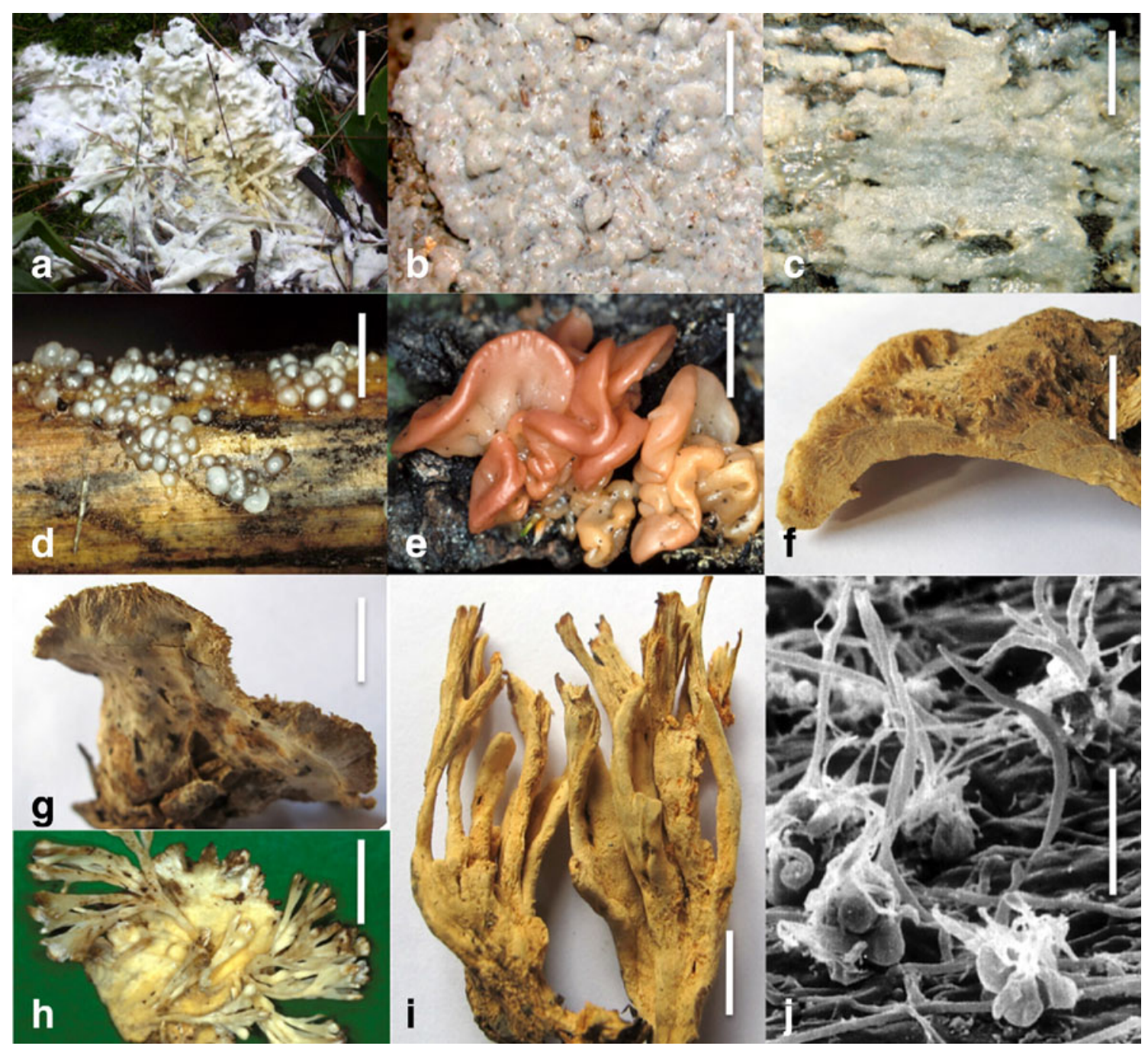

Fig. 1 Basidiocarps of representative species of sebacinalean genera: a Sebacina incrustans, bar $1 \mathrm{~cm}$. b $S$. epigaea, bar $5 \mathrm{~mm}$. c $S$. dimitica, bar $5 \mathrm{~mm}$. d Efibulobasidium albescens, bar $5 \mathrm{~mm}$. e Craterocolla cerasi, bar $1 \mathrm{~cm}$. f Tremellostereum dichroum, bar $2 \mathrm{~cm}$. g Tremelloscypha gelatinosa, bar $4 \mathrm{~cm}$. h Tremellodendron sp. with sebacinoid basal layer, bar $2 \mathrm{~cm}$. i Tremellodendron candidum, bar $2 \mathrm{~cm}$. j Sebacina (Serendipita) vermifera, bar $20 \mu \mathrm{m}$, basidial clusters are scattered on loose generative hyphae, a basidiocarp is lacking. SEM photo P. Blanz. All other photos F. Oberwinkler
The family Sebacinaceae has been proposed by Oberwinkler and Wells (in Wells and Oberwinkler 1982) to cover species of the genera Sebacina, Tremelloscypha (Figs. $1 \mathrm{~g}$ and $2 \mathrm{~d}-\mathrm{g}$ ), and Tremellodendron (Figs. 1h, i and $2 \mathrm{j}, \mathrm{k}$ ). Efibulobasidium (Figs. $1 \mathrm{~d}$ and $2 \mathrm{~h}, \mathrm{i}$ ) was assigned tentatively to the new family. Ryvarden (1986) erected Tremellostereum with a single species, previously called Stereum dichroum Lloyd (Fig. 1f), which shares sebacinoid characters. Based on molecular phylogenetic analyses, Weiß et al. (2004) confirmed Efibulobasidium as a member of the family, including in it also Craterocolla (Figs. 1e and 2a,b), and raising the group to ordinal rank. Molecular phylogenetic evidence for the ectomycorrhizal status of Tremellodendron was found by Walker and Parrent (2004).
Piriformospora indica (Verma et al. 1998), isolated from soil of the Indian Thar Desert as an anamorphic fungus, has dolipores with continuous parenthesomes of the sebacinalean type. The phylogenetic relationship with Sebacinales has been documented by various molecular hypotheses, e.g. Weiß et al. (2004, 2011). A second species, $P$. williamsii, with multinucleate cells, has been recently described by Zuccaro and Weiß in Basiewicz et al. (2012). Based on molecular phylogenetic analyses, enzymatic profiling, genome size estimations and karyotype analyses of five $S$. vermifera strains, $P$. indica, and $P$. williamsii, the authors could identify specific differences in the physiological and molecular parameters inferred from these morphologically very similar strains. 

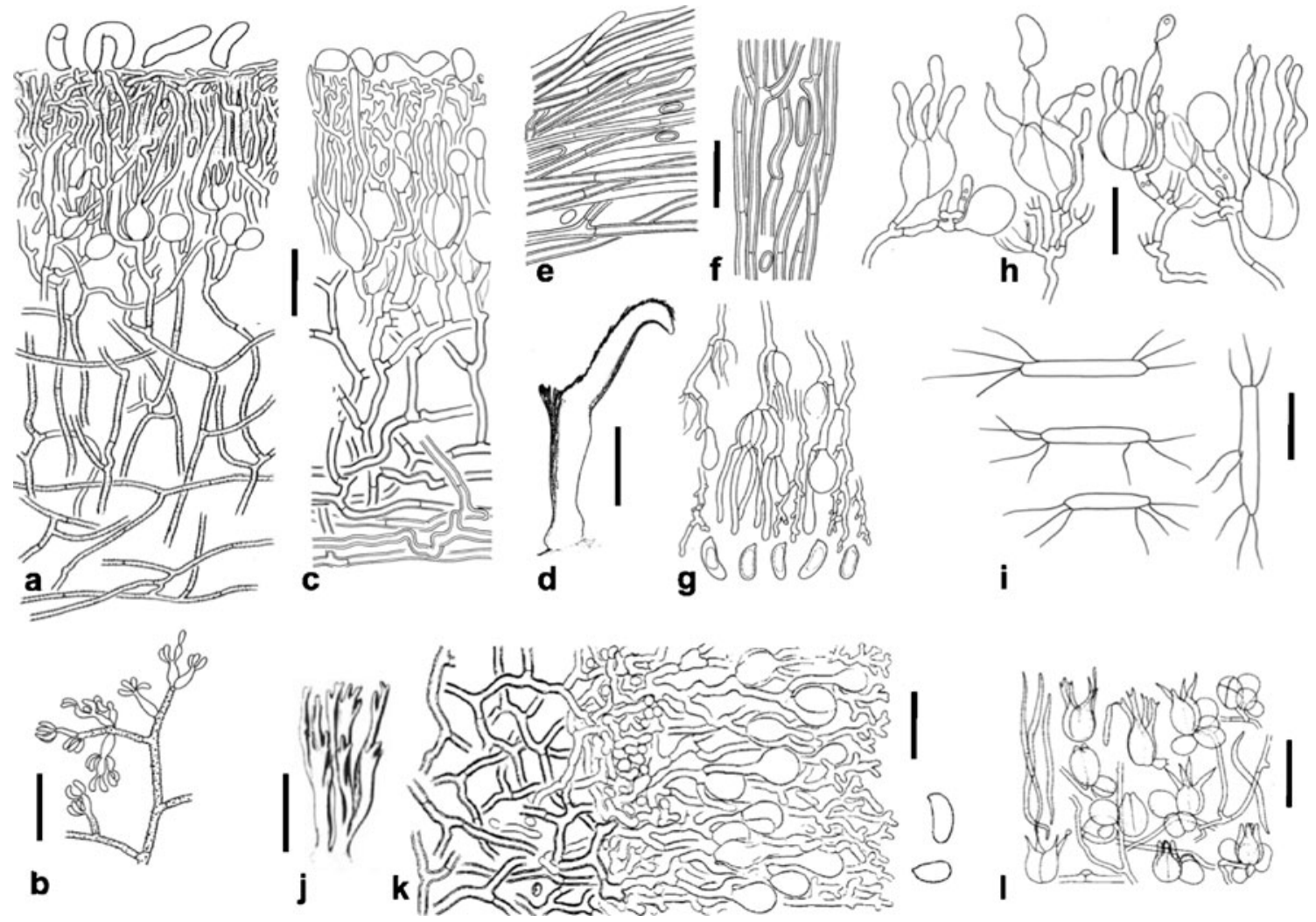

Fig. 2 Teleomorphic and anamorphic stages of Sebacinales. a Craterocolla cerasi, section of hymenium and subhymenium with basidiospores on the hymenial surface, bar $20 \mu \mathrm{m}$. b conidial stage of $C$. cerasi with conidiogenous cells and conidia, bar $20 \mu \mathrm{m}$. c Sebacina incrustans, section of hymenium and subhymenium with basidiospores on the hymenial surface, bar $20 \mu \mathrm{m}$ (from Wells and Oberwinkler 1982). d-g Tremelloscypha gelatinosa; d section of basidiocarp, bar $2 \mathrm{~cm}$, e hyphae of pileus surface, $\mathbf{f}$ hyphae of stipe, $\mathbf{g}$ part of the hymenium with basidia of different developmental stages, dikaryophyses and basidiospores, bar $20 \mu \mathrm{m}$ for e, f, g, (g from Wells and

\section{Ultrastructure of septal pores (Fig. 3)}

Dolipores with continuous parenthesomes are a common ultrastructural marker for Sebacinales, first documented for Sebacina and Tremellodendron by Khan and Kimbrough (1980) and confirmed for Sebacina by Oberwinkler (1985). A basidiomycete with sebacinoid dolipores occurred in living cells of mycorrhizal hair roots of Calluna vulgaris (Bonfante-Fasolo 1980). Ultrastructural studies by Filipello Marchisio et al. (1985) of endophytes of native Italian Dactylorhiza maculata, D. sambucina, and Platanthera bifolia revealed dolipores with continuous parenthesomes, suggesting Sebacina and/or Tulasnella mycobionts. Williams and Thilo (1989) compared the dolipores of multinucleate Rhizoctonias with the dolipore of Sebacina vermifera ss. Warcup and Talbot, reaffirming the earlier findings. Also Currah and Sherburne (1992) studied orchid mycorrhizae forming fungi (ORMs), including Sebacina sp., with identical results. Again, in comparative studies of
Oberwinkler 1982). h Efibulobasidium sp., part of the hymenium with basidia of different developmental stages, bar $20 \mu \mathrm{m}$. i Conidia of Chaetospermum gossypinum derived from cultivated Efibulobasidium albescens, bar $20 \mu \mathrm{m}$ (from Kirschner and Oberwinkler 2009). j, k Tremellodendron candidum (from Wells and Oberwinkler 1982); j basidiocarp, bar $2 \mathrm{~cm}$, $\mathbf{k}$ section of hymenium and subhymenium with basidiospores, bar $20 \mu \mathrm{m}$. I Sebacina (Serendipita) vermifera, hyphae, basidia in different developmental stages, and basidiospores, bar $20 \mu \mathrm{m}$ (from type, Oberwinkler 1964)

selected species of the Rhizoctonia s.l. complex, Andersen (1996), and Müller et al. (1998) were able to document dolipores with continuous parenthesomes. Epulorhiza (Sebacina) strains, isolated from Australian orchids and studied by Gleason and McGee (2001), showed the same ultrastructural characteristics. Dolipores of sebacinoid, tulasnelloid, ceratobasidioid and homobasidiomycetous mycobionts of Ecuadorian ORMs were illustrated by Kottke and Suárez Chacón (2009, Fig. 3d). Sebacina in ectomycorrhizae (ECM) of Carpinus betulus, Corylus avellana were illustrated by Selosse et al. (2002a), in ECM of Tilia sp. by Urban et al. (2003), and Salix waldsteiniana by Garnica et al. (2012).

\section{Phylogenetic hypotheses}

Molecular data led Weiß and Oberwinkler (2001) to conclude that the Sebacinaceae do not belong to the Auriculariales. Their sebacinoid sampling included species of the genera 


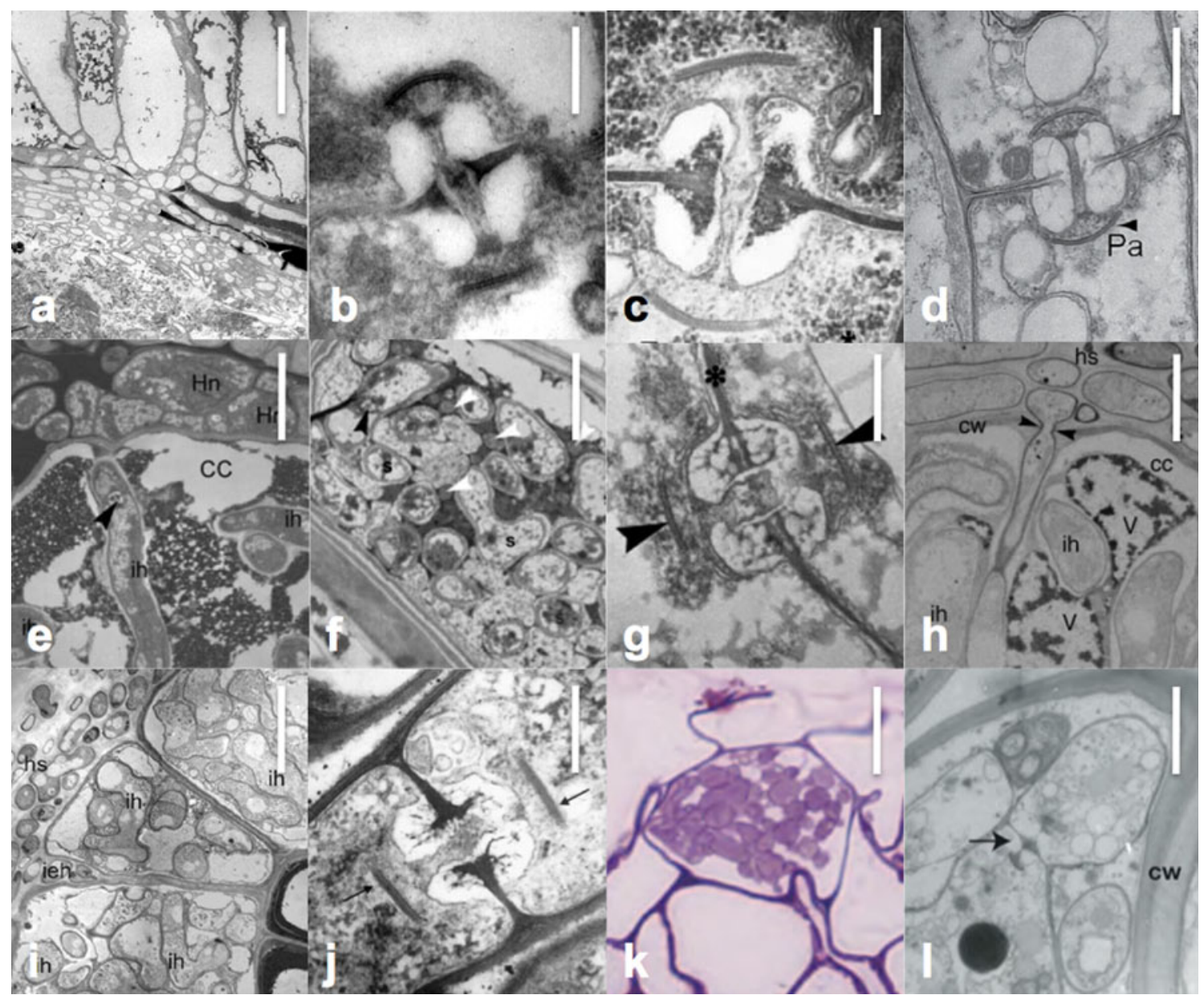

Fig. 3 Transmission electron micrographs (except of k) of sebacinalean mycobiont interactions with plant cells and Sebacina dolipores. a, b Sebacina-Salix waldsteiniana ECM, orig. R. Bauer; a hyphal mantle (below) and Hartig net (above), bar $20 \mu \mathrm{m}$; b Sebacina-type dolipore with continuous parenthesomes, bar $0.5 \mu \mathrm{m}$. c Dolipore from Sebacina-Stelis ORM, bar $0.2 \mu \mathrm{m}$, Suárez et al. (2008). d Dolipore from Sebacina-Sobralia ORM, PA continuous parenthesome, bar $0.5 \mu \mathrm{m}$, Kottke and Suárez Chacón (2009). e Sebacina-Arbutus unedo EEM, cc cortical cell, Hn Hartig net, ih intracellular hyphae, bar $10 \mu \mathrm{m}$, Selosse et al. (2007). f Sebacina-Erica cinerea ERM, intracellular hyphae in hair roots, black arrowhead points to dolipore, white arrowheads point to plant mitochondria, s intracellular sebacinalean hyphae, bar $5 \mu \mathrm{m}$, Selosse et al. (2007). g Sebacina-Gaultheria poeppigii ERM, arrowheads point to continuous parenthesomes, star marks hyphal septal

Craterocolla, Efibulobasidium, Piriformospora, Sebacina, Tremellodendron, and Tremelloscypha. In addition, sebacinoid ectomycorrhizae from various hosts, ericoid mycorrhizae from Gaultheria shallon, orchid mycorrhizae from autotrophic and apochlorotic (= mycoheterotrophic) hosts (e.g. in Selosse et al. 2002b), and jungermannioid mycothalli from the genera Calypogeia and Lophozia were included (Kottke et al. 2003). These taxa represented a well supported monophylum, including two major clades. In following studies, more and more extended samplings of root-derived sebacinalean sequences became available. The originally indicated dichotomy of two intra-sebacinalean clades ("Group A" versus "Group B") wall, bar $0.2 \mu \mathrm{m}$, Selosse et al. (2007). h Sebacina-Cavendishia nobilis CVM, $c c$ cortical cell, $c w$ cell wall, $h s$ hyphal sheath, ih intracellular hyphae, $V$ vacuoles, bar $5 \mu \mathrm{m}$, Setaro et al. (2006a). i SebacinaPsammisia guianensis CVM, ih intracellular mycobiont hyphae, $h s$ hyphal sheath, bar $10 \mu \mathrm{m}$, Setaro et al. (2006b). j Dolipore from a hypha in a Sebacina-Calypogeia mycothallus, arrow points to continuous parenthesome, bar $0.5 \mu \mathrm{m}$, Kottke et al. (2003). k, l Sebacina endophytic in Triticum aestivum, Riess (2009), k light microscopic overview of a host cell of the outer exodermis layer with a sebacinalean endophyte, bar $20 \mu \mathrm{m}$; I intracellular Sebacina hyphae, one with dolipore, cw cell wall, bar $1 \mu \mathrm{m}$. CVM cavendishioid mycorrhiza, $E C M$ ectomycorrhizae, EEM ectendomycorrhizae, ERM ericoid mycorrhiza, ORM orchid mycorrhizae

became gradually more evident (Urban et al. 2003; Weiß et al. 2004; Setaro et al. 2006a; Selosse et al. 2007; Weiß 2007; Selosse et al. 2009, Weiß 2010; Weiß et al. 2011).

The following discrepancies became obvious: (1) Sebacina species based on macromorphological characters do not cluster in a monophylum in molecular hypotheses. The same holds for Efibulobasidium and Tremellodendron. (2) Sebacina vermifera ss. Warcup and Talbot is not identical with the type of $S$. vermifera as described by Oberwinkler (1964). Micromorphological differences in hyphal and basidial morphology may support the separation of both taxa. (3) Sebacina vermifera ss. Warcup and Talbot 


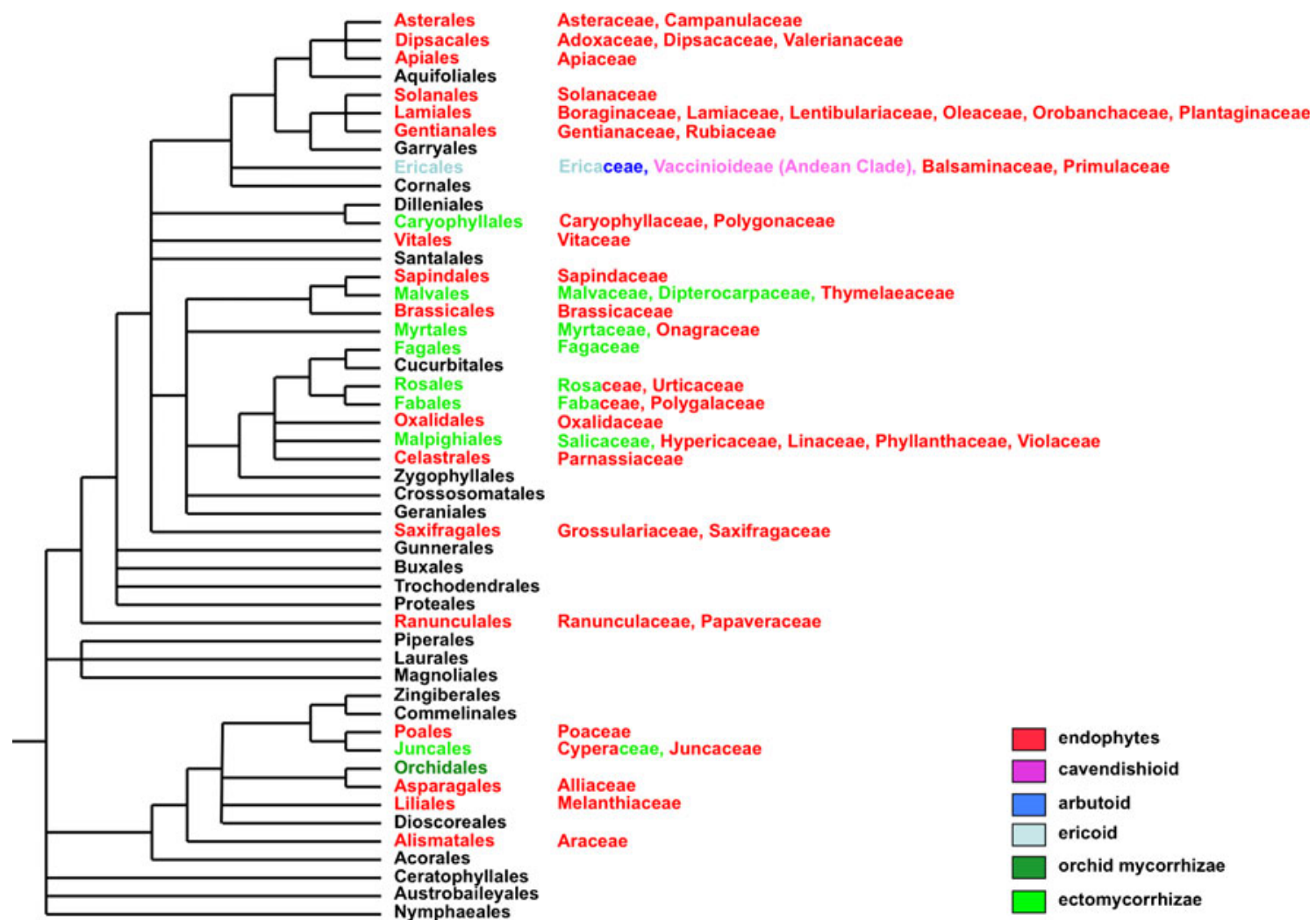

Fig. 4 Distribution pattern and known associations of Sebacinales with angiosperms. Endophytes (red) are predominant, ectomycorrhizae (light green), orchid mycorrhizae (dark green), ericoid mycorrhizae

isolates do not represent a monophyletic group according to molecular hypotheses. Further data are lacking. In addition, the phylogeny of Tremellostereum is unknown, and Chaetospermum spp. and Piriformospora spp. are only known as asexual stages.

In most sebacinalean genera studied in detail, species delimitations based on structural characters appear to be rather difficult or impossible. For molecular species delimitation, a distance threshold of $3 \%$ of ITS1 and ITS2 has been applied to Sebacinales by various authors, as discussed by Setaro et al. (2011).

\section{Biodiversity in sebacinalean mycorrhizae, endophytes and their associations with plants (Figs. 3 and 4)}

Four taxon groups are recognized for structuring the biodiversity in Sebacinales: (1) teleomorphs, (2) anamorphs, (3) mycorrhizae, and (4) root associates, called endophytes, thus circumscribing vaguely morphologically indistinct but presumably physiologically very active fungi, as proven for Piriformospora indica. The most intriguing fact in Sebacinales research is the huge number of environmental sequences that accumulated in a very short time by molecular detection of rootassociated and thallus-associated sebacinalean fungi, (light blue), cavendishioid mycorrhizae (purplish), arbutoid mycorrhizae (blue). Dendrogram after angiosperm phylogeny website, strongly modified

demonstrating here, as in many other domains of microbiology, the power of molecular ecology, but also its limits. Most are not known as organisms, thus hampering further studies heavily.

\section{Sebacinalean ectomycorrhizae (ECM)}

Teleomorphic Sebacinales are known only from Sebacinaceae s.str., and of Serendipita vermifera and Sebacina vermifera ss. Warcup and Talbot (1967) that cluster in Group B. In addition, there are many sequence taxa known from diverse ectomycorrhizal (ECM) hosts. They are reviewed here in a strongly abbreviated version, using host taxa as a guideline. It is noteworthy to consider that most molecular ECM studies before 2004 did not sample and/or identify sebacinalean mycobionts. Given the frequency of these taxa on tropical and temperate ECM hosts (Tedersoo and Nara 2010), they were likely deliberately excluded as contaminants before 2004 .

The comprehensive compilations of ECM data of Agerer (1987-2008) include also identified and/or potential species of Sebacina. Micromorphological, chemical, ecological and colour characters of Sebacina ECMs have been summarized by Agerer (1991, 2006): ECM brownish, short distance exploration types, emanating hyphae clampless and smooth, often with thick walls, cystidia and mantle hyphae dextrinoid, cystidia 
dichotomously, tritomously, or quadritomously branched. The latter character is unexpected, because cystidia are lacking in all known basidiocarps. The ectomycorrhizal lifestyle in fungi, including Sebacinales, has been critically reviewed on a global scale by Tedersoo et al. (2009a). An information system for the characterization and determination of ectomycorrhizae is available as an internet platform (Agerer and Rambold 2004-2009), and another one by Kõljalg et al. (2005).

Pinaceae ECMs of Sebacina incrustans on Picea abies were first reported by Urban et al. (2003). Cline et al. (2004) found Sebacina-ECMs on Pseudotsuga menziesii in Washington State, USA. In a comprehensive study on the diversity and community structure of ECMs in a wooded meadow in Estonia, Tedersoo et al. (2006) recorded Sebacina epigaea and S. incrustans on Picea abies. While studying the host effects on ectomycorrhizal fungal communities in Japanese mixed conifer-broadleaf forests, Ishida et al. (2007) found considerable amounts of Sebacinales mycobionts, misnamed as Exidiaceae, in Abies homolepis and Tsuga sieboldii.

Sebacina sp. appeared as the third dominant ECM of Pinus thunbergii in coastal pine forests in Korea (Obase et al. 2009). Sebacina sp. was recorded from Pinus sylvestris on serpentine soil in East Austria by Urban et al. (2008). Among ectomycorrhizal fungi of Keteleeria davidiana and K. evelyniana of Southwest China, sebacinoids were also present (Ge et al. 2011). Reithmeier (2011) studied the facilitation of ectomycorrhizal colonization of Picea mariana by alternate host plants above treeline in Labrador. Sebacina spp. are essential components in these organismic interactions. Wang and Guo (2010) reported Sebacina sp. as common ECM mycobionts of the Chinese Pinus tabulaeformis, and Wei and Agerer (2011) described two sebacinalean ECMs, Pinirhiza multifurcata and $P$. nondextrinoidea from P. tabulaeformis, verified as Sebacinales Group A taxa by molecular hypothesis based on nLSU sequences. Further, Picea abies and Pinus mugo had sebacinalean ECM mycobionts in the Bavarian Alps (Garnica et al. 2012).

Cyperaceae Mühlmann and Peintner (2008) found Sebacina incrustans as an ECM species in Kobresia myosuroides. A total richness of operational taxonomic units (OTUs) of 70 has been determined in two Kobresia species in the eastern Himalaya, seven of them belonging to Sebacinales (Gao and Yang 2010).

Polygonaceae The circumpolar and arctic-alpine Bistorta vivipara is one of the rare species that can be associated both with glomeralean fungi to form arbuscular mycorrhizae (AMF) and with ECM fungi, including Sebacina sp. (Eriksen et al. 2002; Kauserud et al. 2012). In plants of the Tyrolean Rotmoos glacier forefront, Mühlmann et al. (2008), and in the Bavarian Alps, Garnica et al. (2012) found $S$. incrustans and several unnamed species of Sebacinales as ECM fungi in B. vivipara. Changes in the root-associated fungal communities along a primary succession gradient, analyzed by 454 pyrosequencing, has shown Basidiomycota, including Sebacina, as the dominant fungi by the numbers of OTUs and sequences (Blaalid et al. 2012). Tremelloscypha gelatinosa has been reported for the first time from Yucatan, Mexico by Guzman (2004). It is a common edible fungus in forests with Gymnopodium floribundum, Polygonaceae, in Chiapas, Mexico (Bandala et al. 2011), and is considered as a potential ECM mycobiont of this polygonaceous host.

Betulaceae In a study of Neottia nidus-avis, a nonphotosynthetic orchid, symbionts with fungal-tree associations of sebacinoids have been recorded from Corylus avellana and Carpinus betulus by Selosse et al. (2002b). Tedersoo et al. (2006) found Sebacina spp. on Alnus sp., Betula spp. and Corylus avellana in a wooded meadow in Estonia. As in Pinaceae and Fagaceae, sebacinalean ECMs are present in Japanese mixed forests on Betula maximowicziana, B. grossa, and Carpinus japonica (Ishida et al. 2007). Studies of ECMs in Mexican Alnus forests, supporting the host co-migration hypothesis, also included sebacinalean fungi (Kennedy et al. 2011).

Fagaceae Sebacina ECMs with Fagus sylvatica were recorded in France by Selosse et al. (2002a). In ECM species of the Minnesota oak savanna, Quercus ellipsoidalis and $Q$. macrocarpa, Avis et al. (2003) found Sebacina spp. and Tremellodendron pallidum as mycobionts. In an old-growth Mediterranean forest dominated by $Q$. ilex, Sebacinales ECMs play an essential role (Richard et al. 2005; 2011). Quercirhiza dendrohyphidiomorpha on Q. suber in Portugal (Azul et al. 2006) is considered a sebacinoid ECM (Wei and Agerer 2011). Sebacina sp. was detected by Tedersoo et al. (2006) on Q. robur in Estonia. As mentioned above for Pinaceae and Betulaceae, Fagaceae are also hosts for Sebacinales mycobionts in Japan, as shown for Fagus crenata, F. japonica, and Q. crispula (Ishida et al. 2007). In xeric Californian Q. douglasii woodlands, a high diversity of ECM mycobionts, including Sebacinales, is present (Smith et al. 2007). The ectomycorrhizal community in beech coppices of different age in North Italy (Trento) also includes sebacinoids (Di Marino 2008). ECMs of $Q$. crassifolia in a Mexican tropical cloud forest contained sebacinalean fungi (Morris et al. 2008). Sebacinales ECM in Tasmanian Nothofagus cunninghamii has been found by Tedersoo et al. (2008a, 2009b). Tremellodendron sp. is involved in ECM seasonal dynamics of $Q$. rubra and $Q$. prinus seedlings in the southeastern Appalachian Mountains (Walker et al. 2008). A molecular survey of ectomycorrhizal hyphae in a Californian Quercus-Pinus woodland revealed sebacinalean mycobionts in Q. douglasii and Q. wislizeni (Hynes et al. 2010). Quercus garryana, grown on serpentine and nonserpentine soils in southwestern Oregon, was associated with sebacinalean 
ECMs in both cases (Moser et al. 2009). In a comparative study of $Q$. rubra-associated ECM communities of disturbed urban sites and mature forests, Sebacina sp. has been identified (Karpati et al. 2011). Sebacina epigaea is a mycobiont in ECMs of Castanea sativa in Western Wisconsin (Palmer et al. 2008). Sebacina ECMs were found in both healthy and Phytophthora-infected stands of $C$. sativa in Central Italy (Blom et al. 2009). Fagus sylvatica of subalpine stands in the Bavarian Alps has sebacinalean ECM mycobionts (Garnica et al. 2012).

Juglandaceae Sebacinoid ECMs were present in orchards of cultivated Carya illinoinensis (Bonito et al. 2011).

Rosaceae Ectomycorrhizal diversities on Dryas octopetala and Salix reticulata in an alpine cliff ecosystem have been studied by Ryberg et al. (2009). They recorded Sebacinales as essential components in this highly specialized ecosystem. Within 137 OTUs sequenced from D. octopetala, 6,9\% belonged to Sebacinales (Bjorbækmo et al. 2010). Garnica et al. (2012) also recorded Sebacina mycobionts on D. octopetala ECMs in the Alps. In contrast, Sebacinales were not reported by Harrington and Mitchell (2005a, b) in ECMs associated with a relict population of $D$. octopetala in the Burren, western Ireland, using ECM morphotypes for identification.

Rhamnaceae Sebacinales ECM in Tasmanian Pomaderris apetala has been documented by Tedersoo et al. (2008a).

Fabaceae In Dicymbe corymbosa (Caesalpinioideae) monodominant forests of the Guiana Shield, Henkel et al. (2011) found 172 putative or confirmed ECM species of a broad range of Ascomycota and Basidiomycota, including three species of the Sebacinales, Sebacina incrustans, S. sp., and Tremellodendron ocreatum. In Zambian plantations of Australian eucalypts, native African caesalpinioid trees, Brachystegia longifolia, Isoberlinia angolensis, and Julbernardia paniculata also grew up, the first and last one associated with Sebacinales ECMs of African origin (Jairus et al. 2011).

Myrtaceae Warcup $(1988,1991)$ could show that some strains of Sebacina vermifera were able to form ECMs with eucalypts and other plants, and ORMs with chlorophyllous terrestrial orchids, including Microtis spp. Glen et al. (2002) raised the question whether Sebacinales are common and widespread ectomycorrhizal associates of Eucalyptus marginata in Australian forests. At that time, they discussed three species: Sebacina dimitica, S. epigaea, and S. vermifera ss. Warcup and Talbot. The latter one was not found. ECM in Tasmanian E. regnans has been recorded by Tedersoo et al. (2008a). Co-introduced Australian ECMs of eucalypts in clearcut miombo woodlands in Zambia contained Sebacinales (Jairus et al. 2011). Except for one uncertain strain, the sebacinoids were identified molecularly as of African origin. They also occurred partly on native caesalpinoid trees (see above).

Malvaceae Sebacinales ECMs on Tilia spp. were first found in Lorraine, France, (Selosse et al. 2002a), and then around Vienna, Austria (Urban et al. 2003). Sebacina epigaea and $S$. incrustans were later reported as ECM mycobionts on T. cordata in Estonia (Tedersoo et al. 2006). In a Central European mixed forest, sebacinalean ECMs were frequently detected on Carpinus and Tilia, but not on Fagus (Lang et al. 2011). Tilia $\mathrm{x}$ vulgaris ECMs in Padova city, Italy, carry considerable amounts of Sebacinales ECMs (Alzetta et al. 2012).

Dipterocarpaceae The ectomycorrhizal Pakaraimaea dipterocarpacea of the Guayana region is considered to indicate an ancient Gondwana origin of dipterocarpaceous ECMs, including sebacinalean taxa (Moyersoen 2006). In a lowland mixed-dipterocarp rainforest of Borneo, Peay et al. (2010) studied the ectomycorrhizal community that included Sebacinales, suggesting a potential link between plant and fungal distributions. Sebacinales constituted one of the 17 phylogenetic lineages of ECM mycobionts in a dry deciduous dipterocarp forest in Thailand (Phosri et al. 2012).

Salicaceae In the forefront of the receding Lyman Glacier, Washington, USA, Trowbridge and Jumpponen (2004) found Sebacina vermifera on Salix spp. Because of unclear morphological characters, the species was omitted from further analyses. Sebacina incrustans ECM of the alpine $S$. herbacea on a glacier forefront in the Austrian Alps was very abundant in 2005, but rather rare in 2006 (Mühlmann and Peintner 2008). Salix reticulata together with Dryas octopetala (see above) are rich in sebacinalean ECMs in cliff ledges at Abisko, northern Sweden (Ryberg et al. 2009). In the Bavarian Alps, S. appendiculata and S. waldsteiniana have sebacinalean ECMs (Garnica et al. 2012, compare Fig. 3a,b). Populus tremula ECMs included Sebacina epigaea and S. incrustans in Estonia (Tedersoo et al. 2006). Sebacinales were present in the ECM fungal community of 8-year-old transgenic Populus alba x P. grandidentata of the Valcartier Research Station, Canada (Stefani et al. 2009).

Distribution mechanisms Obviously, in addition to the fungal propagation potentials, as basidiospore and conidium dispersal, natural and human-caused distribution patterns of host taxa are important for the spread of mycobionts. However, it has to be considered that the distributive mechanism for the symbionts is most likely a cooperative one, e.g. ontogenetic stages of the hosts and competitive space occupation of the mycobionts are involved. In addition, diverse abiotic habitat conditions often play a considerable role as determining factors for distribution efficiency. Tedersoo and Nara (2010) 
stated that the general latitudinal gradient of biodiversity is reversed in ECM fungi, including Sebacinales; i.e. the tropics are less ECM-rich than extratropical regions. According to Tedersoo et al. (2010), the holarctic region harbours most of the ECM lineages, including Sebacinales. In addition, a global and austral distribution pattern has been distinguished. Even tropical Dipterocarpaceae and Caesalpinoideae cannot be characterized by specific mycobiont groups. Bahram et al. (2012) found evidence for host range expansions of local symbionts, including sebacinoids, to distantly related host taxa in exotic Pinus sylvestris plantations in relation to native host trees, Carpinus betulus, Fagus orientalis, and Quercus castaneifolia, in the Hyrcanian forests of Iran. Based on molecular evidence, Geml et al. (2012) concluded that longdistance dispersal of some ECM fungi, including Sebacina species in the Northern Hemisphere, may have played a major role in their phylogeographic history. Human-caused introductions of ECMs are common and widespread, and may exceed 200 species (Vellinga et al. 2009). However, species with inconspicuous fruitbodies, as most sebacinalean taxa, are rarely or not reported at all.

Ecology One of the most intriguing facts in ECMs and other mycorrhizae is the high number of mycobionts that are, simultaneously, successively, and potentially associated with one host species. Therefore, Sebacinales are part of a diverse mycobiont community available for interactive functions. In temperate deciduous forests, Sebacinales ECMs seem to co-dominate with those of Russulales and Thelephorales (Weiß et al. 2004; Smith et al. 2007; Tedersoo 2007). Sebacina ECMs as short-distance exploration types (Agerer 2001) in young Picea abies stands of the Bavarian limestone Alps preferred the organic layer (Baier et al. 2006) of soil horizons. Studies of fine-scale distribution patterns of ECM fungi across substrate layers in Estonia showed dominating Sebacinales in the upper coarse woody debris (Tedersoo et al. 2003). They were rare in the lower one and lacking in the other layers. Underground primary succession of ECMs in the volcanic desert on Mount Fuji, Japan, was studied by Nara et al. (2003). Nara (2006) considered Salix reinii as a pioneer for providing compatible ECMs, including Sebacinales, to further colonizers like Betula ermanii and Larix kaempferi. Diverse soil conditions and host trees support the high richness of ECMs, including Sebacinales, in wooded meadows in Estonia (Tedersoo et al. 2006). ECM diversity and community composition, including Sebacinales, in five common Estonian boreal microsites, with Picea abies and Betula pendula, have been analyzed by Tedersoo et al. (2008b). Obviously, ECM communities are determined by the decay type of dead wood that functions as seed bed for trees and fungi. Post-fire, seasonal and annual dynamics of ECM communities in Quercus ilex forests have been examined by de Román and de Miguel (2005) over a 3-year period. A maximum of mycorrhization was found in winter, and an increase of ECMs over the sampling period in the burned stand. In total, however, no significant differences in diversity, species richness, and species composition could be found in comparison with the control plot. Liming led to a reduction of acidophilic ECMs, and in contrast, to an increase of ubiquist mycobionts in ectomycorrhizal communities of the Vosges (Rineau 2008; Rineau and Garbaye 2009). The relative abundance of Sebacina epigaea on root tips of Fagus sylvatica was $1 \%$ in untreated and $2 \%$ in limed plots. The mean contribution of this species to eight potential enzyme activities was high in untreated spruce and beech plots, and varied considerably in limed ones. In naturally regenerating beech forests of North Spain, Sebacina ECMs appeared restricted to unmanaged Fagus sylvatica stands (Goicoechea et al. 2009). In ECM communities associated with Pinus thunbergii in the eastern coastal forests of Korea, Sebacinales mycobionts showed high abundance and frequency (Obase et al. 2009). In the Western Amazonian rainforest of Northeast Ecuador, ECMs had a low diversity but a high host preference (Tedersoo et al. 2010). Sebacina spp. and Tremellodendron pallidum were associated with Coccoloba spp. (Polygonaceae) but not with Guapira spp. and Neea spp. (Nyctaginaceae). Fungal dispersion and host sharing seem to be essential for ECM communities associated with Pakaraimaea dipterocarpacea (Moyersoen 2012). In ECMs, including Sebacinales, of wooded savannas and rain forests of Continental Africa and Madagascar, Tedersoo et al. (2011) found low levels of host preferences and communities little structured by soil parameters. The positive role of host preference and soil origin on mycorrhizal diversity of seedlings was quantitatively documented in ECMs, including Sebacinales, of Pinus armandii, P. massoniana, Castanopsis fargesii, and Lithocarpus harlandii, in natural forests and deforested sites of Sichuan, China, by Ding et al. (2011). There were little changes in seasonal dynamics and in response to drought in sebacinalean ECMs of a Mediterranean forest dominated by Quercus ilex (Richard et al. 2011). ECM networks of adult Pseudotsuga menziesii seemed to be advantageous for their seedlings, especially under drought stress (Bingham and Simard 2012). The dominant OTUs of Pinus montezumae ECMs were composed of Atheliaceae, Cortinariaceae, and Sebacinaceae, but differed on seedlings and adult pines (Reverchon et al. 2012). Surprisingly, Dickie and Moyersoen (2008) did not refer to Sebacinales in their overview towards global aspects of ectomycorrhizal ecology.

Physiology of sebacinalean ECM ECM mycobionts of Sebacinales, except of Sebacina vermifera, have not yet been cultured axenically. Therefore, they have rarely been used in experimental approaches. Sucrose from host plants is mostly hydrolyzed by fungal plant parasites into their monosaccharides by glycosyl hydrolase family 32 enzymes (GH32). Genes 
for such enzymes were lacking in 46 basidiomycetous ECM fungi, with the remarkable exception of Sebacina incrustans (Parrent et al. 2009), but they were present in 16 of 54 surveyed non-mycorrhizal Agaricomycetes. A putatively secreted sucrase was identified in the genome draft of $P$. indica, suggesting a wide-spread distribution of the enzyme in the Sebacinales (Zuccaro et al. 2011).

\section{Orchid mycorrhizae (ORM)}

Studies in orchid mycorrhizae (ORM) have a long tradition. "L'évolution dans la symbiose des orchidées et leurs champignons commensaux" by Bernard (1909), and "Die Wurzelpilze der Orchideen, ihre Kultur und ihr Leben in der Pflanze" by Burgeff (1909) were the first comprehensive publications dealing with the biology of ORMs. Strikingly, the discovery of the symbiotic germination of orchid seeds was made by Bernard on Neottia nidus-avis where Sebacinales are involved (Bernard 1899, see Selosse et al. 2011), but at that time the identification of the mycobiont was impossible. Another outstanding treatment was "Saprophytismus und Symbiose, Studien an tropischen Orchideen" by Burgeff (1932). "Terrestrial orchids from seed to mycotrophic plant" by Rasmussen (1995) is an essential contribution to all aspects of orchid biology in premolecular times. Orchid mycorrhizal research has been summarized by Dearnaley (2007), by Smith and Read (2008) in their famous "Mycorrhizal symbiosis", covering all other aspects of mycorrhizae, and by Kottke and Suárez Chacón (2009). More recently, Dearnaley et al. (2013) reviewed ORM fungi.

A breakthrough in experimental research was the successful isolation and axenic culture of mycobionts, including Sebacina vermifera, of terrestrial Australian orchids by Warcup and Talbot (1967). Molecular techniques had a stimulating impact on ORM research, and the design of a selective primer for Sebacinales' internal transcribed spacer, namely ITS3Seb, by Berbee (Setaro et al. 2006a) was another remarkable step forward for studies of these fungi. The ITS primers and sequences for improved characterization of basidiomycetous ORMs were reviewed by Taylor and McCormick (2007). Further Sebacinales-specific primers were designed by Weiß et al. (2011) and Garnica et al. (2012).

Seedling development of orchids requires fungal assistance. Adult orchids are also associated with mycobionts, green orchids depend on ORMs for mineral supply while mixotrophic, and mycoheterotrophic ones fully depend on ORMs for mineral and carbon nutrition. Predominant mycobionts are Basidiomycota: Sebacinales, Tulasnellales, Ceratobasidiales, Thelephorales, Russulales, and some species of Agaricales. Ascomycota are also known as ORM mycobionts (Dearnaley et al. 2013).

\section{Symbiotic development}

Isolates of Sebacina vermifera-like fungi (Warcup 1971, 1981, 1988, 1991), identified by their teleomorphs and considered as identical with the type species (Oberwinkler 1964), stimulated the germination of Microtis uncinata, and also partly of Caladenia, Cyrtostylis, and Glossodia species. The mycobionts of terrestrial Australian orchids, isolated and identified by Warcup, as summarized by Dearnaley and Le Brocque (2006), comprise Sebacina in Acianthus, Caladenia, Cyrtostylis, Elythranthera, Eriochilus, Glossodia, Leporella, and Microtis. The endangered Caladenia atroclavia, endemic in the Stanthorpe region of Southeast Queensland, has a mycobiont of the Sebacinales (Dearnaley et al. 2009). The fungal isolate is used in ex situ propagation of the host. The functional and genetic diversity of ORMs from single plants of Caladenia formosa was studied by Huynh et al. (2009). They found multiple mycorrhizal strains of one species close to $S$. vermifera s.l., and suggested longer-term growth tests to obtain sufficient information on successive interactive functions. A comparative study of germination, seedling development, and mature plants in Cephalanthera and Epipactis species together with neighboring ectomycorrhizal trees and their simultaneously specific ECM mycobionts, including Sebacinales, in various forests of England, France, Germany, and Finland, has been carried out by Bidartondo and Read (2008) and Tesitelova et al. (2012). One general result of these two studies was that fungal specificity is a bottleneck during germination and development in Cephalanthera but not in Epipactis, which did not show change of its symbionts during development. Sebacinoids were included, but were detected only to $1 \%$ of all unique sequences.

\section{Mycobionts of adult terrestrial orchids}

South Australian orchids of the genus Caladenia and the allied genera Elythranthera, Eriochilus, and Glossodia, are closely associated with Sebacina vermifera s.l. (Warcup 1971). In contrast, these authors found that Diuris mycobionts are Tulasnella calospora, thus indicating patterns of host specificity. Isolates of Rhizoctonia from non-orchids in the Sydney region stimulated the germination of Microtis seeds (Milligan and Williams 1988), in contrast to the natural mycobionts $S$. vermifera and T. calospora, isolated from adult Microtis hosts. Besides dominant Tulasnella and Laccaria mycobionts in European Dactylorhiza majalis, Sebacina was also found in plants of the Copenhagen Botanical Garden by Kristiansen et al. (2001). The changes of ORMs in terrestrial orchids of Hungary and the Czech Republic as a function of the habitat water supply were demonstrated by Illyés et al. (2009). Sebacinoid mycobionts were found in wet habitats in roots of Dactylorhiza incarnata. According to McCormick et al. 
(2004), ORMs of the photosynthetic terrestrial Cephalanthera austinae, Goodyera pubescens, Liparis lilifolia, and Tipularia discolor from the eastern and mid-western USA, comprise Sebacina, although details cannot be found in the data presented. Identification and molecular phylogeny of Epulorhiza isolates from tropical orchids comprised both Sebacina and Tulasnella mycobionts (Ma et al. 2003). Sebacinoid ORMs were detected in Epipactis palustris in a wetland site not accompanied by ectomycorrhizal plants in Northeast Bavaria, Germany (Bidartondo et al. 2004). Shefferson et al. (2005) found that high specificity generally characterizes ORMs in Cypripedium species from North America and Estonia. Mycoendophytes of terrestrial Acianthus, Caladenia and Pterostylis of Southeast Queensland appeared to be specific for their hosts (Bougoure et al. 2005). Sebacina vermifera, originally isolated from Caladenia dilatata (Warcup 1971, 1981), has also been found in C. carnea. The ORM diversity and compatibility of the Australian terrestrial orchids $C$. falcata and Microtis media also include Sebacinales (Bonnardeaux et al. 2007). ORMs of the S. vermifera complex in common and rare Caladenia species were characterized taxonomically and functionally by Wright et al. (2010). The chlorophyllous Stigmatodactylus sikokianus grows in Japan, preferably in the needle litter of Cryptomeria japonica, and is associated with Sebacina mycobionts (Yagame and Yamato 2008; Yagame 2011). In roots of the Chinese Bletilla ochracea, ten mycobionts, including one sebacinoid species, were detected by Tao et al. (2008). The colonization patterns of ORMs in Central Japan appear to be specific for Sebacina sp., a mycobiont in Cephalanthera falcata but not in C. erecta, which is associated with thelephoroids (Matsuda et al. 2009). Sequence homologies of 5.8S rDNAs from Epulorhiza calendulina, isolated from Paphiopedilum species in Thailand (Nontachaiyapoom et al. 2010), were related to Sebacina. Kottke and Suárez Chacón (2009) found Sebacina in the Andean Sobralia rosea (Fig. 3d). Sebacina vermifera strains that were associated with orchid roots could be characterized molecularly and physiologically (Basiewicz et al. 2012). The photosynthetic Mediterranean meadow orchids Anacamptis laxiflora, Ophrys fuciflora, Orchis purpurea, and Serapias vomeracea were found to be partially mycoheterotrophic (Girlanda et al. 2011) and enriched in ${ }^{15} \mathrm{~N}$, compared with neighboring non-orchid plants. In A. laxiflora and S. vomeracea sebacinoid ORMs were detected, in the latter one also by Weiß et al. (2011). In La Réunion, Sebacinales represented $9.5 \%$ of the ORM fungi on the 28 terrestrial orchid species investigated by Martos et al. (2012).

\section{Mycobionts of adult epiphytic orchids}

Besides tulasnelloid fungi, Group B Sebacinales were found in ORMs of epiphytic orchids in an Andean cloud forest
(Suárez et al. 2006), and at La Réunion, Sebacinales represented $23 \%$ of the symbionts in the 45 epiphytic species investigated by Martos et al. (2012). Epiphytic orchids from Ecuadorian mountain rainforests have Group B Sebacinales mycobionts (Suárez et al. 2008, 2009), forming mycorrhizae that were proven ultrastructurally in Stelis spp. (Fig. 3c) and Pleurothallis lilijae.

\section{Mycoheterotrophic and mixotrophic orchids}

Bernard (1899) and Magnus (1900) were the first to study and illustrate the symbiotic germination of the apochlorotic, mycoheterotrophic Neottia nidus-avis in detail. The requirement for locally distributed Sebacina spp., necessary for symbiotic germination and development of the European N. nidusavis, has been shown under natural conditions by McKendrick et al. (2002), while at the same time the sebacinoid mycobionts were detected by Selosse et al. (2002a, b) in roots of adult Neottia nidus-avis. These were demonstrated as ectomycorrhizae on closely growing Picea abies, Pinus sylvestris, Fagus sylvatica, Carpinus betulus, Corylus avellana, Tilia $s p$., and Populus nigra. Sebacinoids were found as the primary ORMs in the North American apochlorotic desert orchid Hexalectris spicta, phylogenetically intermixed with ECM taxa (Taylor et al. 2003). Epipactis microphylla, a mixotrophic species of the Neottieae, occasionally having apochlorotic individuals, was studied by Selosse et al. (2004) to obtain data about its ORM mycobionts. In study sites of France, $78 \%$ of investigated root pieces were colonized by Tuber spp., but other associated fungi also included Sebacinales. Another example of mixotrophy of Cephalanthera damasonium from France, involving Sebacinales among other taxa, has been described by Julou et al. (2005). In a comparative study of mixotrophic green and albino Cephalanthera longifolia from Estonia, Abadie et al. (2006) also found Sebacina in a chlorophyllous plant. Dearnaley (2006) reported sebacinalean endophytes together with saprobic homobasidiomycetes in the mycoheterotrophic Australian Erythrorchis cassythoides. The mycoheterotrophic Aphyllorchis montana and A. caudata from Thailand grow in tropical dipterocarpacean forests, and are associated with diverse ECM fungi including Sebacinales (Roy et al. 2009). Ogura-Tsujita and Yukawa (in Motomura et al. 2010) found a shift to exclusively ECM mycobionts, including sebacinoids, in apochlorotic, mycoheterotrophic Cymbidium species in Japan. A general conclusion was that mycoheterotrophy evolved from mixotrophic ancestors and not directly from autotrophic ones in these orchids. The apochlorotic Lecanorchis taxa from Japan, growing in forests with dominant Castanea and Quercus species, have mostly Lactarius and Russula symbionts, but also mycobionts belonging to Atheliaceae and Sebacina (Okayama et al. 2012). Comparing the nutritional modes of autotrophic and partially 
to fully mycoheterotrophic orchids of the Mediterranean region and the Macaronesian Islands, Liebel et al. (2010) detected sebacinoid ORMs in the apochlorotic Limodorum trabutianum of Sardinia and in Serapias vomeracea of northern continental Italy. Mycoheterotrophic orchids were found to be limited to Mediterranean forests. Abiotic and biotic factors were considered to influence orchid nutritional modes and distribution patterns.

\section{ORM-ECM connections}

Warcup (1988) has reported that some Sebacina vermifera strains from terrestrial Australian orchids, like Microtis spp., are ectomycorrhizal on Eucalyptus and other ECM trees. Bidartondo et al. (2004) and Selosse et al. (2004) presented evidence that also the photosynthetic orchids Epipactis atrorubens, E. distans, E. helleborine, E. microphyllum, Cephalanthera damasonium, and C. rubra, growing in ECM forests of Northeast Bavaria and France, have connections with their neighbouring ECM trees, and that pathways for $\mathrm{C}$ compounds do exist between them. Sebacinales occurred among other fungi in these orchids. The photosynthetic Japanese Platanthera minor is mixotrophic and predominantly associated with Ceratobasidiales ECM fungi
(Yagame et al. 2012), but additional Basidiomycota, including Sebacinales, and Ascomycota were detected.

\section{Commercial aspects}

Dendrobium chrysanthum and D. nobile are medicinally used orchids in Xishuangbanna, Yunnan, South China that are artificially grown from tissue cultures. Because growth rates and quality of these orchids are poor, efforts are being made to apply natural conditions with symbiotic growth (Chen et al. 2012). Five sebacinalean strains could be isolated for further applications in symbiotic germination technologies.

\section{Coevolutionary trends}

Arbuscular mycorrhizae are widespread in Asparagales, but they are not convincingly recorded from orchids (Yukawa et al. 2009). Typical ORMs do already exist in Apostasioideae, the basal group of the Orchidaceae. The five studied Apostasia species had Botryobasidium and Ceratobasidium mycobionts, and Neuwiedia veratrifolia was associated with Ceratobasidium and Tulasnella. Sebacinoids were found in various host taxa (Fig. 5). Basidiomycetous ORMs are

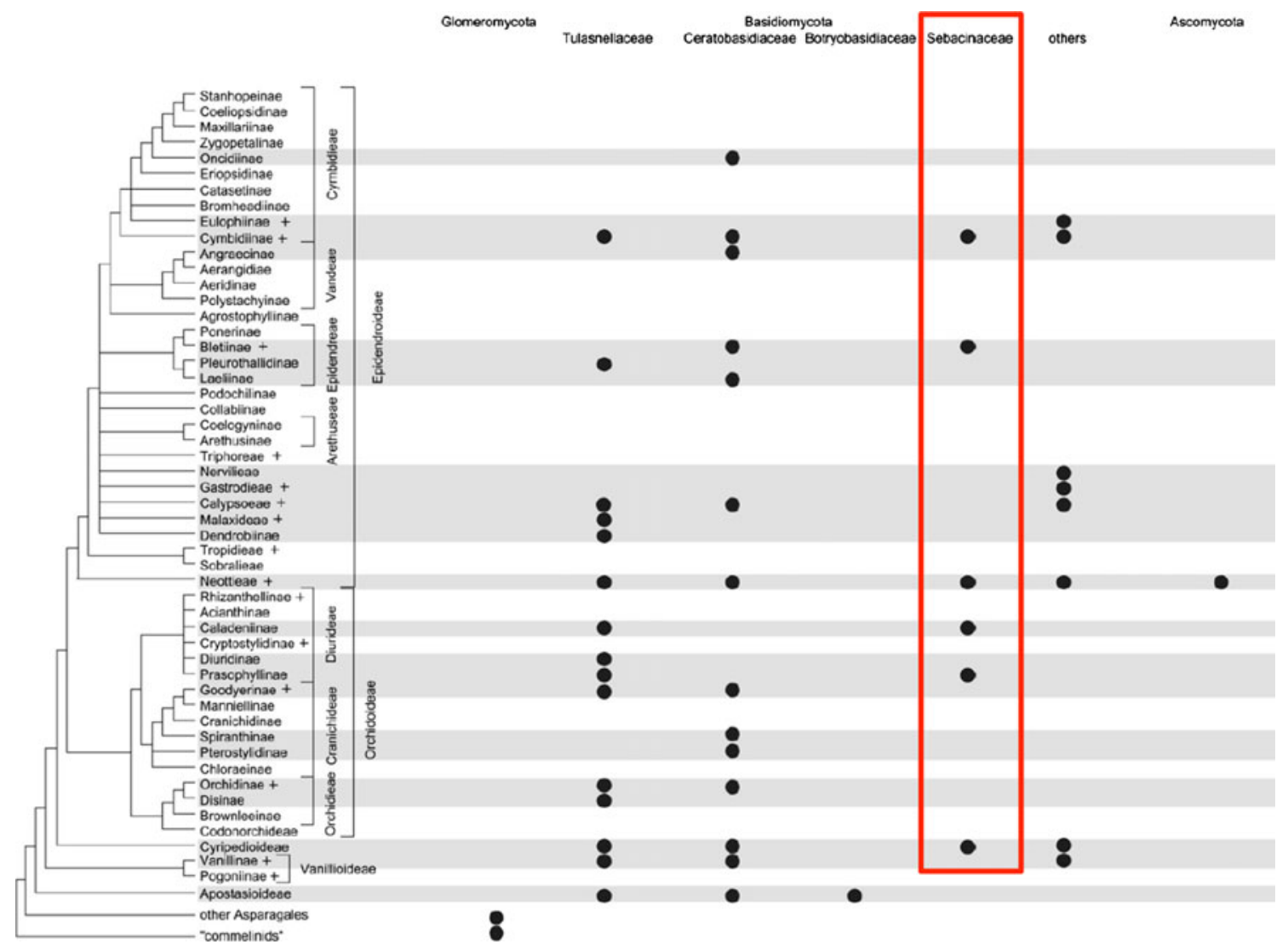

Fig. 5 Distribution pattern of ORM fungi and their hosts. Sebacinaceae marked in red. From Yukawa et al. (2009) 
predominant, and mycobiont switches and host selectivities cannot be explained; however, Cantharellales sensu Hibbett et al. (2007), comprising Tulasnellales and Ceratobasidiales, are assumed to constitute the phylogenetically oldest orchid mycobionts. An unexpected finding was the occurrence of Atractiellomycetes in the roots of the epidendroid Elleanthus, Epidendrum, Maxillaria, and Pleurothallis species of Andean origin in Ecuador (Kottke et al. 2009). The switch of derived orchids to basal basidiomycetous mycobionts is rather enigmatic. In this study, sebacinalean ORMs of Epidendrum, Pleurothallis, Prostechea, Stelis, and several other unidentified orchids were also detected molecularly.

\section{Ectendomycorrhizae (EEM)}

Mycobionts of ectendomycorrhizae (EEM) colonize the root surface with a hyphal sheath, and grow in between and intracellularly in cortical cells. They often belong to ECM taxa. The EEMs include arbutoid and pyroloid mycorrhizal types, and sebacinalean mycobionts belonging to Sebacinales Group A are sometimes involved (e.g. Selosse et al. 2007; Weiß et al. 2011). From the Fango valley in Corsica, with an old-growth Mediterranean forest dominated by Quercus ilex, Richard et al. (2005) reported diverse basidiomycetous mycobionts, including sebacinoid EEMs in Arbutus unedo that represented $18.6 \%$ of the investigated EEMs. Parallel evolutionary paths to mycoheterotrophy in understorey Ericaceae and Orchidaceae were assumed by Tedersoo et al. (2007). They revealed ecological evidence for mixotrophy in Pyroleae, and detected sebacinoid mycobionts in Orthilia secunda and Pyrola chlorantha in Kärla, Saaremaa

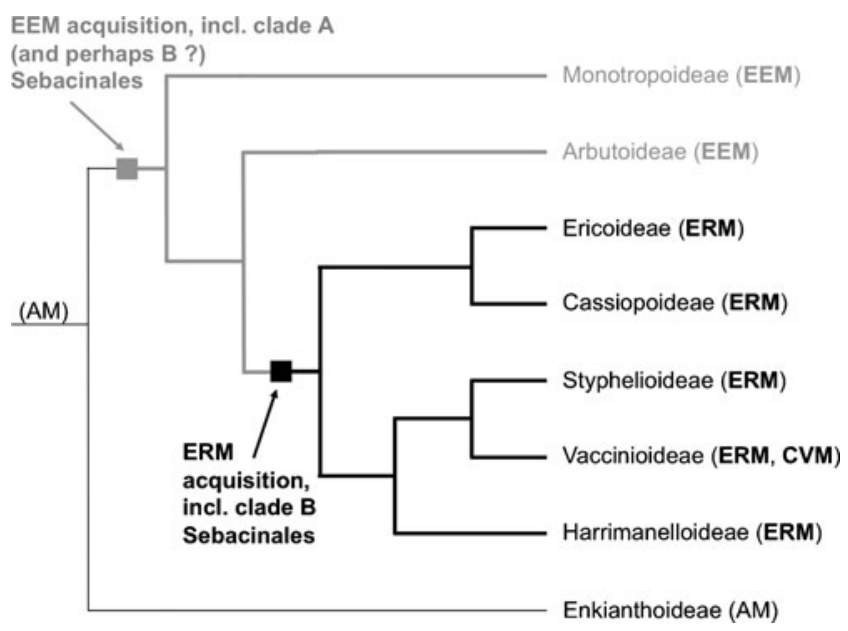

Fig. 6 Phylogeny of Ericaceae and their mycorrhizal types. $A M$ arbuscular mycorrhiza, EEM ectendomycorrhizae, ERM ericoid mycorrhiza, CVM cavendishioid mycorrhiza. Orig. M.-A. Selosse, modified after Selosse et al. (2007), host tree after Freudenstein (1999) and Kron et al. (2002)
Island, Estonia. In addition to sebacinalean taxa of Group B, 13 ectendomycorrhizae with Group A Sebacinas in roots of the basal Ericaceae, Arbutus unedo (Fig. 3e) and Arctostaphylos uva-ursi, were detected by Selosse et al. (2007). Group A and B sebacinalean taxa were also found on Estonian Pyrola rotundifolia by Vincenot et al. (2008). The distribution pattern of mycorrhizal types in Ericaceae allows a coevolutionary hypothesis (Fig. 6). In ericalean mycoheterotrophic pyroloids and monotropoids and in mixotrophic and heterotrophic orchids, nitrogen gains from mycobionts were documented in plants from northeast Bavaria, and from California (Zimmer et al. 2007). In Pyrola secunda, also Sebacina sp. was encountered as a mycobiont. Chlorophyllous Japanese P. asarifolia has a mycoheterotrophic germination of dust seeds (Hashimoto et al. 2012) in which mycobionts of Sebacinales Group B are heavily involved, as they are in some orchids. The mycobionts of adult plants differ considerably in their composition and have more in common with ECM associates of neighboring trees, including Group A and B sebacinalean taxa. Though well documented, this remarkable developmental metamorphosis in changing mycobionts is not understood but concisely commented on by Hynson et al. (2012). In contrast, Matsuda et al. (2012) found various basidiomycetous symbionts of the genera Russula, Amanita, Clavulina, Inocybe, Tomentella and Tricholoma, but no Sebacina in P. japonica in a deciduous broadleaf forest with dominating Quercus serrata and Q.acutissima, in the Mie Prefecture, central Japan. The finding of Group B sebacinalean fungi as EEMs on adult roots of Pyroleae is somewhat unexpected, since EEM fungi normally belong to taxa that are also able to form ECM associations. Until direct observation confirms the molecular data, the fact that Group B Sebacinales are also endophytes (see below) has to be considered. In such a case, DNA of endophytes, instead of EEM fungi, could be sequenced.

\section{Ericoid mycorrhizae (ERM)}

A mycobiont with continuous dolipore parenthesomes was found by Bonfante-Fasolo (1980) in Calluna vulgaris root hairs, suggesting a sebacinoid origin. The basidiomycetes in Gaultheria shallon ericoid mycorrhizae (ERM) from Vancouver Island yielded mixtures of DNA types with predominating Sebacina in the roots; however, none occurred amongst the isolated cultures in which Capronia sp. and Hymenoscyphus ericae were most frequent (Berch et al. 2002; Allen et al. 2003). The cross-communication in ERM and ECM partnerships was reviewed by Vrålstad (2004), especially referring to the interaction between an isolate from the H. ericae aggregate and roots of Pinus sylvestris and Vaccinium myrtillus (Villareal-Ruiz et al. 2004). Selosse et al. (2007) found Group B Sebacinales in 76 ERMs sampled worldwide. Septal pore ultrastructure of hyphae in living host 
cells confirmed the molecular identification (Fig. 3f,g). In North Swedish experimental plots of $V$. myrtillus in a Picea abies forest and $V$. vitis-idaea in a Pinus sylvestris stand, Rhizoscyphus ericae agg., Herpotrichiellaceae and Sebacina spp. provided the most common ERMs (Ishida and Nordin 2010). Artifical nitrogen enrichment did not change the mycobiont species composition and community structures in measurable dimensions in the understorey dwarf shrubs. Neotropical and temperate Vaccinioideae of North America share their Sebacinales communities, thus indicating that hosts and mycobionts co-migrated (Setaro and Kron 2011). The high number of 71 fungal taxa, including Sebacina vermifera-like ones, was observed on roots of the model understorey shrub, Rhododendron maximum, from montane hardwood forests in the southern Appalachians, North Carolina (Wurzburger et al. 2011). However, except for $R$. ericae and Oidiodendron maius, these diverse fungi could not be verified as ERM mycobionts. Nevertheless, it is assumed that the genetic diversity of genes encoding multicopper oxidases in these fungi is important for the regulation of nutrient cycles between the plant and the soil environment. In an investigation of the root endophytes of $R$. fortunei from subtropical Chinese forests, no sebacinalean fungi were detected by Zhang et al. (2009). In a subalpine peat bog and in adjacent dolomitic rock formations of the Bavarian Alps, Garnica et al. (2012) recorded sebacinalean ERMs on Andromeda polifolia, Calluna vulgaris, Rhododendron hirsutum, Vaccinium myrtillus, V. oxycoccum, and V. uliginosum.

\section{Cavendishioid mycorrhizae (CVM)}

Setaro et al. (2006a) studied the ectendomycorrhizal Sebacinales of the Andean Cavendishia nobilis, an endemic, hemiepiphytic species of the Ericaceae in mountain rain forests of southern Ecuador (Fig. 3h). The term "cavendishioid mycorrhiza" (CVM) was introduced to underline the specific characters, as a hyphal sheath, loose hyphae between cortical root cells and inflated intracellular hyphae, likely a derived feature from EEM ancestors (Fig. 6). All CVMs studied were found to be members of Ascomycota and Sebacinales Group B and considered to be specific for the Andean clade of Ericaceae. This assumption could be confirmed by an enlarged sampling of 15 members of the Andean clade ericads with CVMs, in contrast to five other ericaceous hosts with typical ERMs containing intracellular hyphae (Setaro et al. 2006b, Fig. 3i), thus justifying the newly introduced mycorrhizal type.

\section{Mycorrhizal networks and species richness of Sebacinales in tropical mountain forests of South Ecuador}

Highly diverse mycorrhizal types and mycobionts were found in an Ecuadorian mountain rain forest with rich AMF mycobionts. CVMs with sebacinoids seem to be specific for the Andean clade of Ericaceae. Epiphytic orchids have sebacinoid and tulasnelloid ORMs. Partially sequenced ITS and LSU regions from sebacinoid mycobionts in ERMs and ORMs of 67 plants in mountain rain forests of southern Ecuador were analyzed, together with all Sebacinales sequences available from GenBank (Setaro et al. 2011). Clustering optimization revealed that a $1 \%$ LSU distance threshold corresponds to $3 \%$ dissimilarity threshold for ITS. About 8-9 \% of observed Sebacinales MOTUs occur in the study area and $74 \%$ are considered as endemic ones, an interpretation that may be difficult to be verified. An unsaturated sampling for Sebacinales in general and also for the study site became evident by estimation of the species richness. Though there is a high Sebacinales diversity in ERMs and ORMs, a Sebacinales hotspot is lacking.

Fig. 7 Mycobiont associations in liverworts and hornworts. Fungal phylogeny compiled after various authors, phylogeny of plants compiled after several authors in Ligrone et al. (2012). Black lines refer to previous data (see accompanying text), red lines include new reports from Bidartondo et al. (2011)

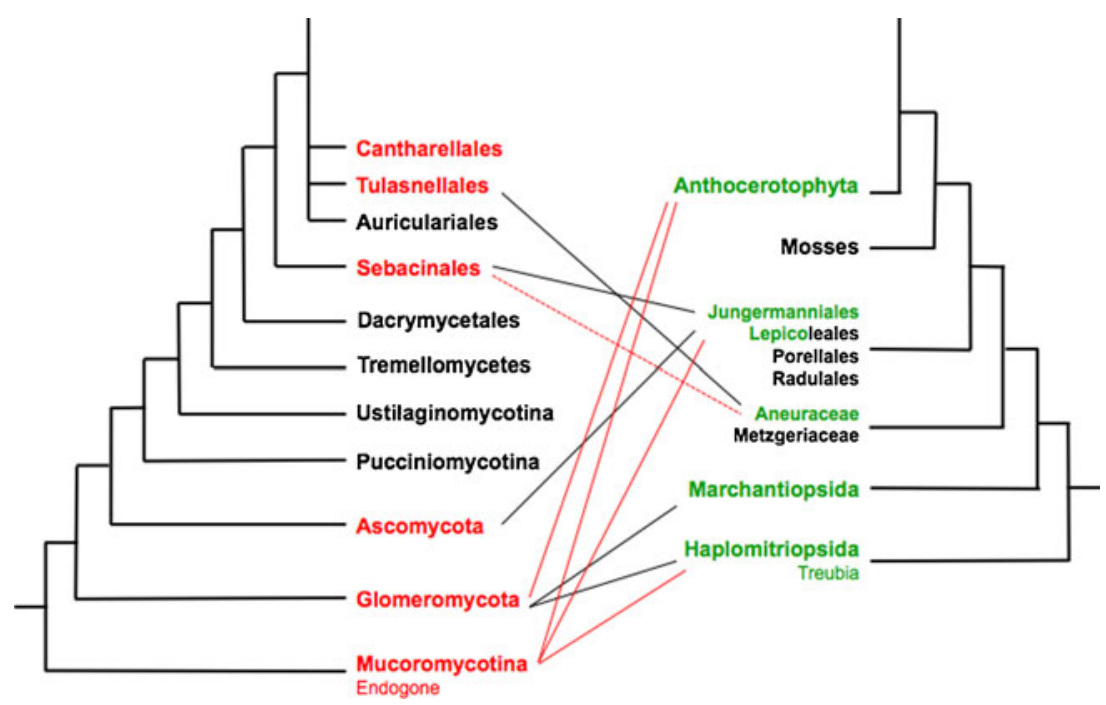




\section{Mycothalli in liverworts and Sebacinales mycobionts in jungermanniales (Fig. 7)}

Liverworts, Marchantiophyta, are considered as the most ancient land plants, and many of them are obligately associated with mycobionts, thus constituting mycothalli. Mycobiont connections between plants for the establishment of liverwort thalli in natural habitats were considered by Turnau et al. (1999). Glomeromycotan species are the predominant fungal partners of thallose liverworts (e.g. Russel and Bulman 2004), and were thought to constitute the oldest ones, too. However, recently Endogone and Endogone-like fungi of the Mucoromycotina were found as mycobionts in thalloid liverworts and hornworts (Bidartondo et al. 2011). They should have given way to Glomeromycota in later phylogenetic lineages (e.g. Redecker et al. 2000), and finally switches to other fungal groups, including Sebacinales, may have occurred. Using molecular techniques, Kottke et al. (2003) detected mycobionts in the foliose liverworts Calypogeia muelleriana, Lophozia incisa and L. sudetica belonging to the Sebacinales cluster of Sebacina vermifera (Fig. 3j); in Aneuraceae, however, exclusively Tulasnella spp. were found as mycobionts (Kottke et al. 2003; Kottke and Nebel 2005; Kottke et al. 2008; Krause et al. 2011). Symbiotic associations of liverworts with fungi were considered as possible ancestors of mycorrhizae by Nebel et al. (2004). Newsham and Bridge (2010) found that Sebacinales associates of the leafy liverwort Lophozia excisa in the southern maritime Antarctic represent the sister group of sebacinalean mycobionts of European Lophozia and Calypogeia species. Basidiomycetous mycobionts of 30 liverwort species from worldwide locations were analyzed by Bidartondo and Duckett (2010). Species of Barbilophozia, Calypogeia, Diplophyllum, Lophozia, Nardia, Sarcogyna, Scapania, Southbya, and Tritomaria, members of the Jungermanniales, were associated with taxa of the S. vermifera complex. Surprisingly, in two Aneura pinguis from UK and USA, Sebacina was also detected, whereas in all other collections of this and other Aneura species, as well as in Lobatiriccardia, Tulasnella spp. were found as mycobionts. Liverworts and early land plant symbioses were reviewed by Selosse (2005), with the suggestion that the possibility of a secondary, late origin for liverwortfungal associations should not be overlooked. This may actually happen for associations with Sebacinales. Jungermannioid mycothalli as well as ericoid and cavendishoid mycorrhizae are so far only known from Sebacinaceae Group B (Weiß et al. 2004).

\section{Sebacinalean endophytes}

The term endophytes, comprising also parasites, was first used by de Bary (1884) for contrasting the epiphytic growth of fungi. Nowadays, the endophytic life of microorganisms is widely considered not to cause any pathogenic symptoms on the hosts. However, the interactions of endophytically living fungi are often much more complex as to be in line with such a simple definition (Porras-Alfaro and Bayman 2011). Hyde and Soytong (2008) compiled the history of studies on endophytes, their definitions, isolation and identification techniques, as well as questions about their biodiversity and role in plant associations. When specific PCR primers for ribosomal DNA of Sebacinales were used on non-basidiomycorrhizal host roots, many cryptic sebacinalean taxa were detected (Riess 2009, Fig. 3k,1, Selosse et al. 2009; Weiß et al. 2011). In these cases, ECMs, ORMs, EEMs, ERMs, and CVMs are excluded, and a specific morphological equivalent is lacking. Thus, we call sebacinalean endophytes mycobionts of roots and thalli of host plants without specific morphological characteristics. Only for Piriformospora indica do detailed studies exist for the fungal-plant interactions in ontogenetic sequences (see below). A plesiomorphic stage has been assumed for sebacinalean endophytes (Selosse et al. 2009, Weiß et al. 2011), but the interactive predominance of the hosts has to be considered as a crucial component. An almost universal presence of Sebacinales as symptomless endophytes is documented by Selosse et al. (2009), Weiß et al. (2011) and Garnica et al. (2012) with proofs for the following plant families: Adoxaceae, Alliaceae, Aneuraceae, Apiaceae, Araceae, Araliaceae, Asteraceae, Balsaminaceae, Boraginaceae, Brassicaceae, Campanulaceae, Caryophyllaceae, Combretaceae, Cyperaceae, Dipsacaceae, Equisetaceae, Euphorbiaceae, Fabaceae s.l., Gentianaceae, Geraniaceae, Grossulariaceae, Onagraceae, Hypericaceae, Juncaceae, Lamiaceae, Lentibulariaceae, Liliaceae, Linaceae, Malvaceae, Melanthiaceae, Oleaceae, Orobanchaceae, Oxalidaceae, Papaveraceae, Parnassiaceae, Phyllanthaceae, Plantaginaceae, Poaceae, Podocarpaceae, Polygalaceae, Polygonaceae, Primulaceae, Ranunculaceae, Restionaceae, Rosaceae, Rubiaceae, Sapindaceae, Saxifragaceae, Selaginellaceae, Solanaceae, Thuidiaceae, Thymelaeaceae, Urticaceae, Valerianaceae, Violaceae, and Vitaceae. Most likely, this is only a minor part of host taxa randomly checked for cryptic sebacinalean endophytes.

\section{Phylogenetic diversity and structure of sebacinoid fungi associated with plant communities}

In a study of eight vegetation communities along an altitudinal gradient between 1,000 and $1,800 \mathrm{~m}$ on Mt. Iseler in the Bavarian Alps, Garnica et al. (2012) found 264 sebacinoid sequences from 70 host species of 44 plant families. They were grouped in 73 MOTUs, containing $39 \%$ singletons, spread over the Sebacinales phylogenetic tree with a preference of Group B. The diversity of MOTUs did not decrease with increasing altitude of the sampling plots. 
MOTUs from grazing meadow, hay meadow, Krummholz formation, and peat bog showed significant phylogenetic clustering. In contrast, sebacinoids from Alpine rose rock association had a random trend in phylogenetic structure, while such trends were not apparent in communities of spruce and ravine forests. Multiple colonizations by sebacinoid mycobionts were found in trees, shrubs and perennial herbs. The available data allow the interpretation that host plants are linked into a common mycelial network within the same site, e.g. an acidophilic group in the peat bog with ERMs. However, Sebacinales community structures appear not to be determined by vegetation structures alone, but rather also by abiotic factors and biotic disturbances.

\section{Piriformospora indica}

While trying to isolate arbuscular mycorrhizal fungi from soil of the Indian Thar Desert, an easily culturable, nonglomeralean anamorphic species, Piriformospora indica, was found by Verma et al. (1998, see above). It remains unclear whether $P$. indica was associated in situ with roots of Prosopis juliflora and/or Ziziphus nummularia, woody shrubs that were growing in the collecting area. Co-cultures with mainly useful plants, but also with Arabidopsis thaliana, resulted in colonization of the epidermal and cortex layers of the roots and in beneficial effects to the host plants. In this part of the review we will focus on the most important findings, and specifically refer to recently published articles (e.g. Basiewicz et al. 2012, Qiang et al. 2012b) and reviews (e.g. Bonfante and Anca 2009; Oelmüller et al. 2009; Shoresh et al. 2010; Singh et al. 2011; Lahrmann and Zuccaro 2012; Qiang et al. 2012a; Zamioudis and Pieterse 2012; Varma et al. 2012).

\section{Root colonization and cellular interactions with experimental host plants}

Infection experiments with Hordeum vulgare and Arabidopsis thaliana have shown that $P$. indica prefers to penetrate living root cells of the maturation zone requiring suppression of the plants' immunity systems (Deshmukh et al. 2006; Jacobs et al. 2011; Qiang et al. 2012b). Fungal hydrolytic enzymes, lectins and small secreted effector proteins (Zuccaro et al. 2011), as well as changes in the plant hormone homeostasis and cellular $\mathrm{Ca}^{2+}$ elevation, are involved in the early colonization process, in which intracellularly growing hyphae are encased by the host plasma membrane (Schäfer et al. 2009; Vadassery and Oelmüller 2009; Vadassery et al. 2009; Matzke et al. 2010; Zuccaro et al. 2011; Lahrmann and Zuccaro 2012). Data of Camehl et al. (2010) and Khatabi et al. (2012) allow the interpretation that $P$. indica induces ethylene synthesis in Arabidopsis and Hordeum roots and that differential ethylene signaling is required to establish root colonization by the mycobiont (Plett 2010). Further jasmonic acid was reported to be an important regulator of induced systemic resistence in this system (Van der Ent et al. 2009). Fungal and plant ABC-transporters and those for nitrogen, carbohydrate, and phosphate (Yadav et al. 2010; Kumar et al. 2011; Zuccaro et al. 2011) are active during this interactive stage, and also in the following one with predominant host cell death, continuous growth and chlamydospore formation of the mycobiont (Schäfer et al. 2007). Fungal and host genome-based analyses are now possible and will allow the identification of the metabolic pathways involved in the interaction. Surprisingly, death of host cells is the consequence of the early interactive phase (Qiang et al. 2012b), allowing the fungus to colonize host cells with then beneficial effects for the autotrophic partner. This process involves early plant protein modifications in the endoplasmic reticulum and at the plasma membrane (Peskan-Berghöfer et al. 2004), and is mediated by an ER stress-triggered caspase-dependent cell death in Arabidopsis (Qiang et al. 2012b). To understand such changing developmental and functional interactive stages is a challenge, and the application of terms like parasite, mycorrhizal mycobiont, or endophyte for the fungus seems problematic (Kogel et al. 2006). Death of some cells is not contradictory to a biotrophic behaviour at tissue level, or a benefit at the organismic level.

\section{Chemical fungal-plant interactions and signaling}

In the interaction of $P$. indica with seedlings of the experimental hosts $A$. thaliana and Nicotiana tabacum, nitrogen was accumulated and the genes for nitrate reductase and for the starch-degrading enzyme glucan-water dikinase (SEX1) were stimulated in the roots (Sherameti et al. 2005). Free sugars and aminoacids are reduced at root tips during fungal colonization, suggesting that the presence of the fungus acts as a sink (Schäfer et al. 2009). One of the first proteins responding to the presence of $P$. indica in the root of $A$. thaliana is a meprin and TRAF homology (MATH) protein in the plasma membrane (Oelmüller et al. 2005). The MATH protein is modified before physical contact between $P$. indica and $A$. thaliana, indicating that recognition of the symbiont is mediated by diffusible molecules that induce modification of the protein in the plasma membrane (Oelmüller et al. 2005). In comparative inoculation experiments of Hordeum with the leaf pathogen Blumeria graminis, $P$. indica chlamydospore pretreated host plants were significantly more resistant than untreated ones (Felle et al. 2009). A correlation with an apoplastic alkalinization response of barley was evident. Inoculation of Zea mays with $P$. indica suppresses further colonization of the host by Fusarium verticillioides through antioxidant enzyme 
activities (Kumar et al. 2009). In addition to altered secondary metabolites, early flowering and increased biomass were also found in Coleus forskohlii when co-cultured with P. indica (Das et al. 2012). The Indian Apiaceae, Centella asiatica, is widely used in Asian traditional medicine. Plants cultured in vitro together with $P$. indica not only showed higher biomass, but also enhanced biosynthesis of asiaticosides (Satheesan et al. 2012).

\section{Growth stimulation of host plants}

Inoculation experiments and application of culture filtrates of P. indica to Artemisia annua, Bacopa monnieri, Nicotiana tabacum, Petroselinum crispum, and Populus tremula resulted in promotion of plant growth and biomass production (Varma et al. 1999). Similar results were reported for the medicinal plants, Spilanthes calva and Withania somnifera under nursery and field growth conditions (Rai et al. 2001). Greenhouse and field pot culture experiments with $P$. indica inoculated Hordeum vulgare resulted in significantly increased growth and photosynthesis rates, as well as an enhanced resistance against the specific leave pathogen Blumeria graminis f. sp. hordei (Achatz 2006). Also under diverse nutrient regimes, an accelerating development of barley plants led to improved grain yield (Achatz et al. 2010). Acceleration in vegetative and fruit development of Lycopersicon esculentum has recently been reported by Andrade-Linares et al. (2012). Promotion of adventitious root formation by $P$. indica in cuttings of Euphorbia, Pelargonium, and Petunia species were reported by Druege et al. (2007). Shahollari et al. (2007) were able to identify a leucine-rich repeat protein induced by $P$. indica that appeared to promote growth and seed production in Arabidopsis thaliana. Indole-3-acetic acid is produced by $P$. indica in liquid culture, and is assumed to affect plant growth as shown in sterile cultures of A thaliana by Sirrenberg et al. (2007). Vadassery et al. (2008) suggested that $P$. indica-induced cell division and elongation in Arabidopsis requires a specific auxin to cytokinin ratio for root and shoot growth, and that growth promotion is independent of the root architecture. However, in Brassica campestris ssp. chinensis and A. thaliana, growth is not stimulated by $P$. indica myceliumsynthesized auxin (Lee et al. 2011). Accordingly, it was recently shown by the use of $P$. indica RNAi strains compromised in IAA and ILA production that fungal derived auxin is not required for growth promotion, but is involved in the biotrophic colonization of barley roots, leaving the option open whether $P$. indica-elicited host auxin biosynthesis modulates plant development and defense (Hilbert et al. 2012). Growth stimulation in A. thaliana by $P$. indica can be initiated by stimulating phosphatidic acid (PA) synthesis with consequent activation of the 3-phosphoinositide dependent kinase 1 (PDK1) and the AGC kinase oxidative signalinducible1 (OXI1) that is involved in reactive oxygen species dependent responses for root hair elongation, and in defense against bacterial and oomycetous infections (Hirt et al. 2011; Camehl et al. 2011; Rentel et al. 2004; Petersen et al. 2009). In P. indica-colonized roots, OXI1 and PDK1 gene expression is upregulated, while defense genes are downregulated by the influence of the mycobiont, indicating that the host's growth response, and not defense induction, is mediated by the PLD-PDK1-OXI1 cascade during $P$. indica colonization. Congruently, Arabidopsis mutants of the proteins OXI1 and PDK1 kinases display no longer growth stimulation by P. indica (Camehl et al. 2011).

\section{Improvement of resistance and tolerance of host plants}

Waller et al. (2005) found that reprogramming of Hordeum vulgare by $P$. indica is associated with an elevated antioxidative capacity due to an activation of the glutathioneascorbate cycle, thus improving salt-stress tolerance, resistance to the leaf pathogen powdery mildew Blumeria graminis f. sp. hordei, and yield. Molitor et al. (2011) showed that the increased resistance in barley leaves due to $P$. indica priming is associated with a faster induction of expression of transcripts for pathogenesis-related and heat shock encoding genes after $B$. graminis inoculation in $P$. indica colonized compared to non-colonized barley plants. Increased systemic resistance by $P$. indica was proven also for the stem base pathogen Pseudocercosporella herpotrichoidea and the root parasite Fusarium culmorum by Serfling et al. (2007) and for Golovinomyces orontii parasitic on Arabidopsis leaves, which required cytoplasmic localization of the nonexpressor of pathogenesis related genes (NPR1) and jasmonic acid signaling, while it is independent of salicylatebased mechanisms (Stein et al. 2008). The symptom severity was significantly reduced in these cases as well as under field experiments with $P$. herpotrichoides; however, not in the case of Blumeria. It was suggested that Central European temperatures are not well suited for $P$. indica under field conditions (Serfling et al. 2007). There is evidence that $P$. indica confers drought stress tolerance to Arabidopsis (Sherameti et al. 2008), indicated by the upregulation of the salt-induced and drought-induced ring finger 1, the calcineurin B-like protein, and the histone acetyltransferase after exposure to drought stress in the leaves of $P$. indica-colonized seedlings. Rodriguez and Redman (2008) questioned the increase of antioxidant systems induced by $P$. indica in the host. However, using salt-sensitive and salttolerant cultivars of Hordeum vulgare for colonization experiments with P. indica, Baltruschat et al. (2008) suggested that antioxidants may play a role in inherited, as well as in 
mycobiont-mediated, plant tolerance to salinity. In Brassica campestris ssp. chinensis, $P$. indica retarded a drought-induced reduction of photosynthesis rate by avoiding degradation of chlorophylls and thylakoid proteins (Sun et al. 2010).

\section{Transitions in trophic stages and experimental host range}

Trophic stages in $P$. indica-plant cellular interactions change considerably during the ontogeny of the mycobiont, thus hampering to apply a simple terminology. In general, there is growing consensus that only few interactive organismic dependencies can be easily categorized (Newton et al. 2010a). Piriformospora indica and its host-dependent development is a good example to characterize the different steps functionally, as has been done under various experimental approaches. The steps are: (1) intracellular growth of the mycobiont, (2) limited cell death of the host, and (3) chemical signaling to initiate growth, biosynthesis of metabolites, defense, and resistance responses of the host. General biochemical and genetic principles appear to be involved in these interactions. Otherwise, the broad experimental host range of angiosperms (e.g. Varma et al. 2001; Molitor and Kogel 2009), could not have been applied in experimental studies (see Sebacinalean endophytes). So far, there are no plant species known that cannot be colonized by $P$. indica (Klute 2011), the 145 tested until 2009 (Oelmüller et al. 2009) referring exclusively to experimental approaches. Oelmüller et al. (2009) report on a vast geographical distribution of $P$. indica from Asia, South America and Australia. We cannot verify such distribution patterns from original publications. In contrast, to our knowledge, $P$. indica has been isolated only once from the Indian Thar desert, and this strain has been used as the only one in all experimental studies carried out so far.

\section{Genome, transcriptome and secretome of Piriformospora indica}

The genome of $P$. indica has a size of about $25 \mathrm{Mb}$ and contains 11,769 gene models with very little $(4.7 \%)$ repetitive DNA (Zuccaro et al. 2009; Zuccaro et al. 2011). Compared to the relatively small genome, the large number of predicted open reading frames (ORFs) with an average distance between genes of $530 \mathrm{bp}$, indicates that $P$. indica possesses a gene dense genome (Zuccaro et al. 2011). In eukaryotes, the existence of significant gene redundancy is considered an important element in their molecular evolution (Li et al. 2010). In P. indica, the occurrence of multiple gene copies with similar functions could therefore have contributed to the wide experimental host range displayed by this mycobiont. Within the gene families that expanded in the $P$. indica genome, a broad range of hydrolytic enzymes could be identified, such as members of the GH10, GH11 and GH61, metallopeptidases of the families M36 and M43 and proteins containing the cellulose binding domain CBM1. In contrast to ECM mycobionts in which glycoside hydrolases and peroxidases are reduced or lacking, gene families encoding hydrolytic enzymes are typical in saprotrophic fungi. Therefore, it is not surprising that the $P$. indica hydrolytic machinery displays considerable similarity with expanded gene families for hydrolytic processes in white rot fungi (Lahrmann and Zuccaro 2012). A significant enrichment for protein binding domains (WD domain, G-beta repeat-WD40; NACHT domain; tetratricopeptide repeat-TPR 4 domain), together with proteins most probably involved in signaling and regulation of cellular responses to stress and nutrient availability (NB-ARC, Galpha protein, F-box, RAS and RHO families), was reported by Zuccaro et al. (2011). These expansions may help $P$. indica to sense and couple signals received from the external environment with the intracellular signaling pathways, and to quickly respond and adapt to different plant signals and host metabolic states. Proteins with carbohydrate binding functions (e.g. protein containing LysM, WSC or CBM1 domains) were also reported to be exceptionally expanded in the P. indica genome (Zuccaro et al. 2011; Lahrmann and Zuccaro 2012). Plants recognize microbial invaders (pathogens or mutualistic symbionts) by detecting conserved microbial structures: the so-called microbe-associated molecular patterns (MAMPs, or more specifically pathogen-associated molecular patterns, PAMPs). Among MAMPs, chitin and flagellin are most probably the best known. Perception of MAMPs leads to an extracellular oxidative burst, which requires the production of reactive oxygen species (ROS), a potent signaling molecule in the plant immune response. The success of microbes to invade plants reflects their ability to evade and/or to reprogram host metabolism and to manipulate the plant immune response. It was recently reported that during colonization of the intercellular spaces of the leaves by Cladosporium fulvum, the cause of leaf mold in Solanum lycopersicum, the fungus secretes effector proteins to establish disease, one of which, Ecp6 (for extracellular protein 6), is a chitin-binding lectin that contains LysM domains (de Jonge et al. 2010). This effector was shown to mediate virulence through perturbation of chitin-triggered host immunity. During infection, Ecp6 sequesters chitin oligosaccharides that are released from the cell walls of invading hyphae to prevent elicitation of host immunity. Recently, it was shown by Jacobs et al. (2011) that this symbiont can evade detection and suppresses immunity triggered by various microbe-associated molecular patterns. Because LysM effectors are widely conserved in the fungal kingdom and have been implied several 
times in host immune suppression by fungal pathogens (Marshall et al. 2011), it was suggested that the existence of multiple gene copies for the LysM domain containing proteins in $P$. indica might play a role in evading host defense (Zuccaro et al. 2011; Lahrmann and Zuccaro 2012).

Besides gene family expansions in $P$. indica, Zuccaro et al. (2011) reported on the lack of genes for nitrogen metabolism and for biosynthesis of toxic secondary metabolites (e.g. polyketide synthases and non-ribosomal peptide synthases), which was implicated in biotroph-associated genomic adaptations (Spanu et al. 2010). Not unexpectedly, coexistent genomic traits for saprotrophic and biotrophic lifestyles exist in $P$. indica that correspond with ontogenetic interactive stages of the mycobiont with its experimental hosts. Also, the presence of small secreted proteins (SSPs, $<300$ amino acids) supports a biotrophic life phase that may comprise some $10 \%$ of the plant-induced genes during early stages of Hordeum vulgare colonization (Zuccaro et al. 2011). A newly detected putative protein effector family, DELD, shows a common motive of seven amino acids, RSIDELD, indicating a common functional role in mycobiont-host interactions (Klute 2011; Zuccaro et al. 2011). Similar to effector proteins in other plant-associated fungi, members of the DELD family have an increased expression in planta and were associated with transposable elements (Zuccaro et al. 2011; Spanu 2012). The ability of P. indica to colonize living cells biotrophically and dead cells saprotrophically is reflected in its transcriptome. Comparisons in protein blast searches and gene expression studies documented that the genes induced during colonization of living roots of $H$. vulgare are more similar to the genes of the ectomycorrhizal Laccaria bicolor, whereas $P$. indica genes induced on dead roots have higher similarity to those of the saprotroph Coprinopsis cinerea (Zuccaro et al. 2011). The relationship between the predicted secreted proteins and the total gene content of fungi has been calculated by Lowe and Howlett (2012). For P. indica, the large proportion of approximately 1,600 secreted proteins was found, similar to those in the rice blast fungus Magnaporthe ory$z a e$, and roughly double in size compared to the number (867) given by Zuccaro et al. (2011), using a more stringent cut-off threshold for the prediction of secreted proteins.

\section{Sebacina vermifera agg}

The anamorphic Piriformospora indica and related species of the $S$. vermifera species complex can grow in various host plants endophytically. Because $S$. vermifera can easily be cultivated on artificial media (Warcup and Talbot 1967; Warcup 1971, 1981, 1988; Bougoure et al. 2005), it is increasingly used for experimental studies, mostly in approaches complementary to those of $P$. indica. Both induce positive growth effects and stronger resistance against abiotic and biotic stress factors in Hordeum vulgare (Deshmukh et al. 2006). Barazani et al. (2005) found that $P$. indica and $S$. vermifera increase growth performance at the expense of herbivore resistance in Nicotiana attenuata. By inhibiting ethylene signaling, S. vermifera promotes the growth and fitness of N. attenuata (Barazani et al. 2007). Colonization of $H$. vulgare roots by $P$. indica, as well as by $S$. vermifera, causes systemic resistance against the specifically parasitic Blumeria graminis f. sp. hordei (Waller et al. 2007). An enhanced production of podophyllotoxins in cocultures of Linum album cells with $P$. indica and $S$. vermifera were reported by Baldi et al. (2010). In vitro and pot culture experiments of Thymus vulgaris with $P$. indica or $S$. vermifera improved plant growth, oil yield and the percentage of thymol (Dolatabadi et al. 2011a). Similar experiments were carried out with the host plant Foeniculum vulgare, and comparable positive results were obtained (Dolatabadi et al. 2011b). Panicum virgatum, co-cultivated with S. vermifera under well watered and under drought conditions produced significantly higher biomass than noninoculated plants (Ghimire and Craven 2011). It is tempting to infer that many Group B Sebacinales may be influential, if not beneficial, endophytes of plants.

\section{Endobacteria of Piriformospora indica and Sebacina vermifera agg}

The intracellular presence of bacteria in mycorrhizal fungi has been reported since transmission electron microscopy provided unambiguous evidence. They were detected in aging ECMs (Berndt et al. 1990), but also considered as helper-bacteria in triple associations (Duponnois and Garbaye 1990, 1991; Buscot 1994; Garbaye 1994). The $\alpha$-proteobacterium Rhizobium radiobacter was found to be stably associated within hyphal cells and chlamydospores of $P$. indica by Sharma et al. (2008). Also in S. vermifera isolates, species-specific associations with Acinetobacter, Paeniobacillus and Rhodococcus spp. were detected. In addition, attempts to obtain bacteria-free $P$. indica and $S$. vermifera strains in axenic cultures failed. However, it was possible to isolate $R$. radiobacter and to inoculate Hordeum vulgare seedlings, showing growth promotion and systemic resistance to Blumeria graminis f. sp. hordei. Systemic resistance in Arabidopsis thaliana against Golovinomyces orontii could be induced by $R$. radiobacter (Sharma 2008). Fungal and/or bacterial shares in the plant responses have not been elucidated so far. However, the possibility exists that bacterium-originated $\mathrm{N}$-acyl homoserine lactones are involved in stimulating plant responses (Schikora et al. 2011). Rhizobium radiobacter is considered to be identical 
with Agrobacterium tumefaciens, a soil-borne pathogen (Newton et al. 2010b) that can lack virulence genes. It can be expected that future studies reveal an interphylum network of nutritional interactions, as recently shown for AMF fungi (Ghignone et al. 2012).

\section{Potential applications}

The beneficial effects of Piriformospora indica and Sebacina vermifera s.l. mycobionts on experimental host plants, comprising increased growth, seed and metabolite yield, stimulation of systemic defence against parasites, and improved resistance towards abiotic and biotic stresses, are well documented. Thus, the application of these mycobionts for improved cultivation of useful plants has been tested under various experimental designs. Considering natural growth conditions, both $P$. indica from India, and $S$. vermifera strains from Australia would be exotic inoculants with uncertain ecological adaptations, at least for North temperate regions. Any further development of Sebacinales as inoculants for plants would have to demonstrate their ability to persist in plants over the long term, especially under natural conditions.

Sebacinalean endophytes have a worldwide distribution and an unparalleled interactive spectrum with land plants. Considering the distributional and ecological diversities, it is highly enigmatic that only two Piriformospora species and several strains of $S$. vermifera could be isolated and kept in axenic cultures so far. This statement does not include saprotrophic taxa, like species of the genera Craterocolla and Efibulobasidium. The cryptic diversity of the Sebacinales, and their great importance for research in mycorrhizae and potential applications in agriculture, were discussed by Weiß (2007, 2010). Varma et al. (2012) predict biotechnological applications of P.indica in agriculture, floriculture, viticulture and the reclamation of contaminated soils.

\section{Synthesis}

The ubiquitous distribution and association with land plants in all mycorrhizal types, except AMFs, recognized so far, , is a unique feature of sebacinalean fungi. There is strong evidence for an originally endophytic lifestyle of Sebacinales. These endomycobionts were recorded with molecular techniques and partly verified by their micromorphology and ultrastructure. Their enormous cryptic biodiversity, indicated by environmental sequence taxa, is unparalleled in Basidiomycota, and their present inaccessibility as organisms is most challenging. Unfortunately, it appears to be extremely difficult with the techniques available today to gain a better understanding of this enigmatic diversity.
However, on the other hand, there are the model organisms Piriformospora indica and Sebacina vermifera. The remarkable outcome of new data in these species through experimental studies was and remains very stimulating. The sequenced genomes of both open new perspectives for analyzing fungalplant interactions, and also analyzing their co-evolutionary patterns. Present studies focus on experimental investigations with Arabidopsis thaliana, a most unexpected but obviously perfectly functional host.

Acknowledgments FO is grateful for the invitation by Katarzyna Turnau to talk about Sebacinales at the ISS 7 Congress, "The earth's vast symbiosphere", Krakow, 2012. This initiated the preparation of a comprehensive review. We thank Paul Blanz and Sabrina Setaro for critically reviewing the manuscript and the DFG (German Research Council) for funding Sebacinales research, partly cited here.

\section{References}

Abadie J-C, Püttsepp Ü, Gebauer G, Faccio A, Bonfante P, Selosse M-A (2006) Cephalanthera longifolia (Neottieae, Orchidaceae) is mixotrophic: a comparative study between green and nonphotosynthetic individuals. Can J Bot 84:1462-1477

Achatz B (2006) Untersuchungen zum Einfluss des Wurzelendophyten Piriformospora indica auf das Wachstum von Hordeum vulgare, die Resistenz gegen Blumeria graminis f. sp. hordei und die Genexpression in den Blättern. Dissertation, University of Marburg

Achatz B, von Rüden S, Andrade D, Neumann E, Pons-Kühnemann J, Kogel K-H, Franken P, Waller F (2010) Root colonization by Piriformospora indica enhances grain yield in barley under diverse nutrient regimes by accelerating plant development. Plant Soil 333:59-70

Agerer R (1987-2008) Colour atlas of ectomycorrhizae, 1st-14th delivery. Einhorn, Schwäbisch Gmünd

Agerer R (1991) Characterization of ectomycorrhizae. In: Norris JR, Read DJ, Varma AK (eds) Techniques for the study of mycorrhiza. Methods in microbiology, vol 23. Acad Press, London et al., pp 25-73

Agerer R (2001) Exploration types of ectomycorrhizae - a proposal to classify ectomycorrhizal mycelial systems according to their patterns of differentiation and putative ecological importance. Mycorrhiza 11:107-114

Agerer R (2006) Fungal relationships and structural identity of their ectomycorrhizae. Mycol Progr 5:67-107

Agerer R, Rambold G (2004-2009, First posted on 2004-06-01; most recent update: 2009-01-26) DEEMY - an information system for characterization and determination of ectomycorrhizae. www.deemy.de München, Germany

Allen TR, Millar T, Berch SM, Berbee ML (2003) Culturing and direct DNA extraction find different fungi from the same ericoid mycorrhizal roots. New Phytol 160:255-272

Alzetta C, Scattolin L, Scopel C, Accordi SM (2012) The ectomycorrhizal community in urban linden trees and its relationships with soil properties. Trees $26: 751-767$

Andersen TF (1996) A comparative taxonomic study of Rhizoctonia sensu lato employing morphological, ultrastructural and molecular methods. Mycol Res 100:1117-1128

Andrade-Linares DR, Müller A, Fakhro A, Schwarz D, Franken P (2012) Impact of Piriformospora indica on tomato. In: Varma A, Kost G, Oelmüller R (eds) Sebacinales: forms, functions and biotechnological application. Springer, Berlin, in press 
Avis PG, McLaughlin DJ, Dentinger BC, Reich PB (2003) Long-term increase in nitrogen supply alters above- and below-ground ectomycorrhizal communities and increases the dominance of Russula spp. in a temperate oak savanna. New Phytol 160:239-253

Azul AM, Agerer R, Freitas H (2006) "Quercirhiza dendrohyphidiomorpha" +Quercus suber L. Descr Ectomyc 9(10):87-91

Bahram M, Kõljalg U, Kohout P, Mirshahvaladi S, Tedersoo L (2012) Ectomycorrhizal fungi of exotic pine plantations in relation to native host trees in Iran: evidence of host range expansion by local symbionts to distantly related host taxa. Mycorrhiza. doi:10.1007/s00572-012-0445-z

Baier R, Ingenhaag J, Blaschke H, Götlein A, Agerer R (2006) Vertical distribution of an ectomycorrhizal community in upper soil horizons of a young Norway spruce (Picea abies [L.] Karst.) stand of the Bavarian limestone Alps. Mycorrhiza 16:197-206

Baldi A, Farkya S, Jain A, Gupta N, Mehra R, Datta V, Srivastava AK, Bisaria VS (2010) Enhanced production of podophyllotoxins by co-culture of transformed Linum album cells with plant growthpromoting fungi. Pure Appl Chem 82:227-241

Baltruschat H, Fodor J, Harrach BD, Niemczyk E, Barna B, Gullner G, Janeczko A, Kogel K-H, Schäfer P, Schwarczinger I, Zuccaro A, Skoczowski A (2008) Salt tolerance of barley induced by the root endophyte Piriformospora indica is associated with a strong increase in antioxidants. New Phytol 180:5011-5510

Bandala VM, Montoya L, Villegas R (2011) Tremelloscypha gelatinosa (Sebacinales) from tropical deciduous Gymnopodium forests in southern Mexico. Mycotaxon 118:147-157

Barazani O, Benderoth M, Groten K, Kuhlemeier C, Baldwin IT (2005) Piriformospora indica and Sebacina vermifera increase growth performance at the expense of herbivore resistance in Nicotiana attenuata. Oecologia 146:234-243

Barazani O, von Dahl CC, Baldwin IT (2007) Sebacina vermifera promotes the growth and fitness of Nicotiana attenuata by inhibiting ethylene signaling. Plant Phys 144:1223-1232

Basiewicz M, Weiß M, Kogel K-H, Langen G, Zorn H, Zuccaro A (2012) Molecular and phenotypic characterization of Sebacina vermifera strains associated with orchids, and the description of Piriformospora williamsii sp. nov. Fungal Biol, doi:10.1016/ j.funbio.2011.11.003

Berch SM, Allen TR, Berbee ML (2002) Molecular detection, community structure and phylogeny of ericoid mycorrhizal fungi. Plant Soil 244:55-66

Berkley MJ, Broome CE (1848) Notices of British fungi. Annals Magaz Nat Hist 2:259-268

Bernard N (1899) Sur la germination de Neottia nidus-avis. Comp Rend Acad Sci 128:1253-1255

Bernard N (1909) L'évolution dans la symbiose des orchidées et leurs champignons commensaux. Ann Sci Nat Bot 9:1-196

Berndt R, Kottke I, Oberwinkler F (1990) Ascomycete mycorrhizas from pot-grown silver fir seedlings (Abies alba Mill.). New Phytol 115:471-482

Bidartondo MI, Duckett JG (2010) Conservative ecological and evolutionary patterns in liverwort-fungal symbioses. Proc R Soc B 277:485-492

Bidartondo MI, Read DJ (2008) Fungal specificity bottlenecks durings orchid germination and development. Molec Ecol 17:3707-3716

Bidartondo MI, Burghardt B, Gebauer G, Bruns TD, Read DJ (2004) Changing partners in the dark: isotopic and molecular evidence of ectomycorrhizal liaisons between forest orchids and trees. Proc R Soc Lond B 271:1799-1806

Bidartondo MI, Read DJ, Trappe J, Merckx V, Ligrone R, Duckett JG (2011) The dawn of symbiosis between plants and fungi. Biol Lett 7:574-577

Bingham MA, Simard SW (2012) Mycorrhizal networks affect ectomycorrhizal fungal community similarity between conspecific trees and seedlings. Mycorrhiza 22:317-326
Bjorbækmo MFM, Carlsen T, Brysting A, Vrålstad T, Høiland K, Ugland KI, Geml J, Schumacher T, Kauserud H (2010) High diversity of root associated fungi in both alpine and arctic Dryas octopetala. BMC Plant Biol 10:244

Blaalid R, Carlsen T, Kumar S, Halvorsen R, Ugland KI, Fontana G, Kauserud H (2012) Changes in the root-associated fungal communitties along a primary succession gradient analysed by 454 pyrosequencing. Molec Ecol 21:1897-1908

Blom JM, Vannini A, Vettraino AM, Hale MD, Godbold DL (2009) Ectomycorrhizal community structure in a healthy and Phytophthora-infected chestnut (Castanea sativa Mill.) stand in central Italy. Mycorrhiza 20:25-38

Bonfante P, Anca I-A (2009) Plants, mycorrhizal fungi, and bacteria: a network of interactions. Annu Rev Microbiol 63:363-383

Bonfante-Fasolo P (1980) Occurrence of a basidiomycete in living cells of mycorrhizal hair roots of Calluna vulgaris. Trans $\mathrm{Br}$ Mycol Soc 75:320-325

Bonito G, Brenneman T, Vilgalys R (2011) Ectomycorrhizal fungal diversity in orchards of cultivated pecan (Carya illinoinensis; Juglandaceae). Mycorrhiza 21:601-612

Bonnardeaux Y, Brundrett M, Batty A, Dixon K, Koch J, Sivasithamparam K (2007) Diversity of mycorrhizal fungi of terrestrial orchids: compatibility webs, brief encounters, lasting relationships and alien invasions. Myc Res 111:51-61

Bougoure JJ, Bougoure DS, Cairney JW, Dearnaley JD (2005) ITSRFLP and sequence analysis of endophytes from Acianthus, Caladenia and Pterostylis (Orchidaceae) in southeastern Queensland. Mycol Res 109:452-460

Bourdot H, Galzin A (1927) Hyménomycètes de France, Hetérobasidiés - Homobasidiés gymnocarpes. Sceaux

Burgeff H (1909) Die Wurzelpilze der Orchideen, ihre Kultur und ihr Leben in der Pflanze. Gustav Fischer Verlag, Jena

Burgeff H (1932) Saprophytismus und symbiose, studien an tropischen orchideen. Gustav Fischer Verlag, Jena

Buscot F (1994) Ectomycorrhizal types and endobacteria associated with ectomycorrhizas of Morchella elata (Fr.) Boudier with Picea abies (L.) Karst. Mycorrhiza 4:223-232

Camehl I, Sherameti I, Venus I, Bethke G, Varma A, Lee J, Oelmüller R (2010) Ethylene signalling and ethylene-targeted transcription factors are required for balancing beneficial and non-beneficial traits in the symbiosis between the endophytic fungus Piriformospora indica and Arabidopsis thaliana. New Phytol 185:1062-1073

Camehl I, Drezwiezki C, Vadassery J, Shahollari B, Sherameti I, Forzani C, Munnik T, Hirt H, Oelmüller R (2011) The OXI1 kinase pathway mediates Piriformospora indica-induced growth promotion in Arabidopsis. PloSPathogens 7(5):e1002051

Chen J, Wang H, S-X G (2012) Isolation and identification of endophytic and mycorrhizal fungi from seeds and roots of Dendrobium (Orchidaceae). Mycorrhiza 22:297-307

Cline ET, Ammirati JF, Edmonds RL (2004) Does proximity to mature trees influence ectomycorrhizal fungus communities of Douglasfir seedlings? New Phytol 166:993-1009

Currah RS, Sherburne R (1992) Septal ultrastructure of some fungal endophytes from boreal orchid mycorrhizas. Mycol Res 96:583-587

Das A, Kamal S, Shakli NA, Sherameti I, Oelmüller R, Dua M, Tuteja N, Johri AK, Varma A (2012) The root endophyte fungus Piriformospora indica leads to early flowering, higher biomass and altered secondary metabolites of the medicinal plant, Coleus forskohlii. Plant Signal Behav 7(1):103-112

de Bary A (1884) Vergleichende Morphologie und Biologie der Pilze, Mycetozoen und Bacterien. Verlag von Wilhelm Engelmann, Leipzig

de Jonge R, van Esse HP, Kombrink A, Shinya T, Desaki Y, Bours R, van der Krol S, Shibuya N, Joosten MH, Thomma BP (2010) Conserved fungal LysM effector Ecp6 prevents chitin-triggered immunity in plants. Science 329:953-955 
de Román M, de Miguel AM (2005) Post-fire, seasonal and annual dynamics of the ectomycorrhizal community in a Quercus ilex L. forest over a 3-year period. Mycorrhiza 15:471-482

Dearnaley JDW (2006) The fungal endophytes of Erythrorchis cassythoides - is this orchid saprophytic or parasitic? Australas Mycol 25:51-57

Dearnaley JDW (2007) Further advances in orchid mycorrhizal research. Mycorrhiza 17:475-486

Dearnaley JDW, Le Brocque AF (2006) Endophytic fungi associated with Australian orchids. Australas Plant Conserv 15:7-9

Dearnaley JDW, Murray AJ, Mathieson MT (2009) Molecular identification of a mycorrhizal Sebacinaceae from the endangered Caladenia atroclavia (black clubbed spider orchid). Australas Mycol 28:45-50

Dearnaley JDW, Martos F, Selosse M-A (2013) Orchid mycorrhizas: molecular ecology, physiology, evolution and conservation aspects. In: Hock B (ed) The Mycota IX. Springer, Berlin, Heidelberg, in press

Deshmukh S, Hückelhoven R, Schäfer P, Imani J, Sharma M, Weiss M, Waller F, Kogel K-H (2006) The root endophytic fungus Piriformospora indica requires host cell death for proliferation during mutualistic symbiosis with barley. Proc Natl Acad Sci USA 103:18450-18457

Di Marino E (2008) The ectomycorrhizal community structure in beech coppices of different age. Dissertation, Universities of Padova and Munich

Dickie IA, Moyersoen B (2008) Towards a global view of ectomycorrhizal ecology. New Phytol 180:263-265

Ding Q, Liang Y, Legendre P, He X-H, Pei K-Q, Du X-J, Ma K-P (2011) Diversity and composition of ectomycorrhizal community on seedling roots: the role of host preference and soil origin. Mycorrhiza 21:669-680

Dolatabadi KH, Goltapeh EM, Moieni A, Jaimand K, Sardrood BP, Varma A (2011a) Effect of Piriformospora indica and Sebacina vermifera on plant growth and essential oil yield of Thymus vulgaris in vitro and in vivo experiments. Symbiosis 53:29-53

Dolatabadi KH, Goltapeh EM, Jaimand K, Rohani N, Varma A (2011b) Effects of Piriformospora indica and Sebacina vermifera on growth and yield of essential oil in fennel (Foeniculum vulgare) under greenhouse conditions. J Basic Microbiol 51:33-39

Druege U, Baltruschat H, Franken P (2007) Piriformospora indica promotes adventitious root formation in cuttings. Sci Hortic 112:422-426

Duponnois, Garbaye J (1990) Some mechanisms involved in growth stimulation of ectomycorrhizal fungi by bacteria. Can J Bot 68:2148-2152

Duponnois, Garbaye J (1991) Effect of dual inoculation of Douglas fir with the ectomycorrhizal fungus Laccaria laccata and mycorrhization helper bacteria (MHB) in two bare-root forest nurseries. Plant Soil 138:169-176

Eriksen M, Bjureke KE, Dhillion SS (2002) Mycorrhizal plants of traditionally managed grasslands in Norway. Mycorrhiza 12:117123

Felle HH, Waller F, Molitor A, Kogel K-H (2009) The mycorrhiza fungus Piriformospora indica induces fast root-surface $\mathrm{pH}$ signaling and primes systemic alkalinization of the leaf apoplast upon powdery mildew infection. MPMI 22:1179-1185

Filipello Marchisio V, Berta G, Fontana A, Marzetti Mannina F (1985) Endophytes of wild orchids native to Italy: their morphology, caryology, ultrastructure and cytochemical characterization. New Phytol 100:623-641

Freudenstein JV (1999) Relationships and character transformation in Pyroloideae (Ericaceae) based on ITS sequences, morphology, and development. Syst Bot 24:398-408

Gao Q, Yang ZL (2010) Ectomycorrhizal fungi associated with tow species of Kobresia in an alpine meadow in the eastern Himalaya. Mycorrhiza 20:281-287
Garbaye J (1994) Helper bacteria: a new dimension to the mycorrhizal symbiosis. New Phytol 128:197-210

Garnica S, Riess K, Bauer R, Oberwinkler F, Weiß M (2012) Phylogenetic diversity and structure of sebacinoid fungi associated with plant communities along an altitudinal gradient. FEMS Microbiol Ecol. doi:10.1111/j.1574-6941.2012.01473.x

Ge Z-W, Smith ME, Zhang Q-Y, Yang ZL (2011) Two species of the Asian endemic genus Keteleeria form ectomycorrhizas with diverse fungal symbionts in southwestern China. Mycorrhiza. doi:10.1007/s00572-011-0411-1

Geml J, Timling I, Robinson CH, Lennon N, Nusbaum HC, Brochmann C, Noordeloos ME, Taylor DL (2012) An arctic community of symbiotic fungi assembled by long-distance dispersers: phylogenetic diversity of ectomycorrhizal basidiomycetes in Svalbard based on soil and sporocarp DNA. J Biogeogr 39:74-88

Ghignone S, Salvioli A, Anca I, Lumini E, Ortu G, Petiti L, Cruveiller S, Bianciotto V, Piffanelli P, Lanfranco L, Bonfante P (2012) The genome of the obligate endobacterium of an AM fungus reveals an interphylum network of nutritional interactions. ISME J 6:136145

Ghimire SR, Craven KD (2011) The ectomycorrhizal fungus Sebacina vermifera enhances biomass production of Switchgrass (Panicum virgatum L.) under drought conditions. Appl Environ Microbiol. doi:10.1128/AEM.05335-11

Girlanda M, Segreto R, Cafasso D, Liebel HT, Rodda M, Ercole E, Cozzolino S, Gebauer G, Perotto S (2011) Photosynthetic Mediterranean meadow orchids feature partial mycoheterotrophy and specific mycorrhizal associations. Am J Bot 98:1148-1163

Gleason FH, McGee PA (2001) Septal pore cap ultrastructure of fungi identified as Epulorhiza sp. (sensu Sebacina) isolated from Australian orchids. Australas Mycol 21:12-15

Glen M, Tommerup IC, Bougher NL, O'Brien PA (2002) Are Sebacinaceae common and widespread ectomycorrhizal associates of Eucalyptus species in Australian forests? Mycorrhiza $12: 243-247$

Goicoechea N, Closa I, de Miguel AM (2009) Ectomycorrhizal communitites within beech (Fagus sylvatica L.) forests that naturally regenerate from clear-cutting in northern Spain. New Forest $38: 157-175$

Guzman G (2004) Los hongos de la Peninsula de Yucatan (Mexico) V. Nuevas observaciones y nuevos registros. Rev Mex Micol 18:7-13

Harrington TJ, Mitchell DT (2005a) Ectomycorrhizas associated with a relict population of Dryas octopetala in the Burren, western Ireland. I. Distribution of ectomycorrhizas in relation to vegetation and soil characteristics. Mycorrhiza 15:425-433

Harrington TJ, Mitchell DT (2005b) Ectomycorrhizas associated with a relict population of Dryas octopetala in the Burren, western Ireland. II. Composition, structure and temporal variation in the ectomycorrhizal community. Mycorrhiza 15:435-445

Hashimoto Y, Fukukawa S, Kunishi A, Suga H, Richard F, Sauve M, Selosse M-A (2012) Mycoheterotrophic germination of Pyrola asarifolia dust seeds reveals convergences with germination in orchids. New Phytol 195:620-630

Henkel TW, Aime MC, Chin MML, Miller ST, Vilgalys R, Smith ME (2011) Ectomycorrhizal fungal sporocarp diversity and discovery of new taxa in Dicymbe monodominant forests of the Guiana shield. Biodivers Conserv. doi:10.1007/s10531-011-0166-1

Hibbett DS, Binder M, Bischoff JF, Blackwell M, Cannon PF, Eriksson OE, Huhndorff S, James T, Kirk PM, Lücking R, Lumbsch HL, Lutzoni F, Matheny PB, McLaughlin DJ, Powell MJ, Redhead S, Schoch CL, Spatafora JW, Stalpers JA, Vilgalys R, Aime MC, Aptroot A, Bauer R, Begerow D, Benny GL, Castlebury LA, Crous PW, Dai Y-C, Gams W, Geiser DM, Griffith GW, Gueidan C, Hawksworth DL, Hestmark G, Hosaka K, Humber RA, Hyde KD, Ironside JE, Kõljalg U, Kurtzman CP, Larsson KH, Lichtwardt R, Longcore J, Miadlikowska J, Miller A, 
Moncalvo J-M, Mozley-Standridge S, Oberwinkler F, Parmasto E, Reeb V, Rogers JD, Roux C, Ryvarden L, Sampaio JP, Schüßler A, Sugijama J, Thorn RG, Tibell L, Untereiner WA, Walker C, Wang Z, Weir A, Weiß M, White MM, Winka K, Yao Y-J, Zhang N (2007) A higher-level phylogenetic classification of the fungi. Mycol Res 111:509-547

Hilbert M, Voll LM, Ding Y, Hofmann J, Sharma M, Zuccaro A (2012) Indole derivative production by the root endophyte Piriformospora indica is not required for growth promotion but for biotrophic colonization of barley roots. New Phytol 196:520-534

Hirt H, Garcia AV, Oelmüller R (2011) AGC kinases in plant development and defense. Plant Signal Behav 6:1030-1033

Huynh TT, Thomson R, Mclean CB, Lawrie AC (2009) Functional and genetic diversity of mycorrhizal fungi from single plants of Caladenia formosa (Orchidaceae). Ann Bot 104:757-765

Hyde KD, Soytong K (2008) The fungal endophyte dilemma. Fungal Divers 33:163-173

Hynes MM, Smith ME, Zasoski RJ, Bledsoe CS (2010) A molecular survey of ectomycorrhizal hyphae in a California Quercus-Pinus woodland. Mycorrhiza 20:265-274

Hynson NA, Jolles D, Madsen TP (2012) A case of Pyrola plantlets with picky palates leads to new insights on mycoheterotrophic seedlings and the fungi that feed them. New Phytol 195:503-506

Illyés Z, Halász K, Rudnóy S, Ouanphanivanh N, Garay T, Bratek Z (2009) Changes in the diversity of the mycorrhizal fungi of orchids as a function of the water supply of the habitat. J Appl Bot Food Qual 83:28-36

Ishida TA, Nordin A (2010) No evidence that nitrogen enrichment affect fungal communities of Vaccinium roots in two contrasting boreal forest types. Soil Biol Biochem 42:234-243

Ishida TA, Nara K, Hogetsu T (2007) Host effects on ectomycorrhizal fungal communities: insight form eight host species in mixed conifer-broadleaf forests. New Phytol 174:430-440

Jacobs S, Zechmann B, Molitor A, Trujillo M, Petutschnig E, Lipak V, Kogel K-H, Schäfer P (2011) Broad-spectrum suppression of innate immunity is required for colonization of Arabidopsis roots by the fungus Piriformospora indica. Plant Phys 156:726-740

Jairus T, Mpumba R, Chinoya S, Tedersoo L (2011) Invasion potential and host shifts of Australian and African ectomycorrhizal fungi in mixed eucalypt plantations. New Phytol 192:179-187

Julou T, Burghardt B, Gebauer G, Berveilleir D, Damesin C, Selosse M-A (2005) Mixotrophy in orchids: insight from a comparative study of green individuals and non-photosynthetic individuals of Cephalanthera damasonium. New Phytol 166:639-653

Karpati AS, Handel SN, Dighton J, Horton TR (2011) Quercus rubraassociated ectomycorrhizal fungal communities of disturbed urban sites and mature forests. Mycorrhiza 21:537-547

Kauserud H, Kumar S, Brysting AK, Nordén J, Carlsen T (2012) High consistency between replicate 454 pyrosequencing analyses of ectomycorrhizal plant root samples. Mycorrhiza 22:309-315

Kennedy PG, Garibay-Orijel R, Higgins LM, Angeles-Arguiz R (2011) Ectomycorrhizal fungi in Mexican Alnus forests support the host co-migration hypothesis and continental-scale patterns in phylogeography. Mycorrhiza 221:559-568

Khan S, Kimbrough JW (1980) Septal structure in some genera of the Tremellaceae. Can J Bot 58:55-60

Khatabi B, Molitor A, Lindermayr C, Pfiffi S, Durner J, von Wettstein D, Kogel K-H, Schäfer P (2012) Ethylene supports colonization of plant roots by the mutualistic fungus Piriformospora indica. PLoS One 7(4):e35502

Kirschner R, Oberwinkler F (2002) Sebacina allantoidea sp. nov. Cryptogam Mycol 23:129-133

Kirschner R, Oberwinkler F (2009) Supplementary notes on Basidiopycnis hyalina (Basidiomycota, Atractiellales) and its anamorph. Mycotaxon 109:29-38
Klute A (2011) Detection and characterization of secreted proteins form Piriformospora indica during Arabidopsis roots colonization. PhD Thesis, Univ Gießen

Kogel K-H, Franken P, Hückelhoven R (2006) Endophyte or parasite —what decides? Curr Opin Plant Biol 9:358-363

Kõljalg U, Larsson KH, Abarenkov K, Nilsson RH, Alexander IJ, Eberhardt U, Erland S, Høiland K, Kjøller R, Larsson E, Pennanen T, Sen R, Taylor AFS, Tedersoo L, Vrålstad T, Ursing BM (2005) UNITE: a database providing web-based methods for the molecular identification of ectomycorrhizal fungi. New Phytol 166:1063-1068

Kottke I, Nebel M (2005) The evolution of mycorrhiza-like associations in liverworts: an update. New Phytol 137:330-334

Kottke I, Suárez Chacón JP (2009) Mutualistic, root-inhabiting fungi of orchids, identification and functional types. In: Pridgeon AM, Suárez JP (eds) Proc Sec Sci Conf Andean Orchids., pp 84-99

Kottke I, Beiter A, Weiss M, Haug I, Oberwinkler F, Nebel M (2003) Heterobasidiomycetes form symbiotic associations with hepatics: Jungermanniales have sebacinoid mycobionts while Aneura pinguis (Metzgeriales) is associated with a Tulasnella species. Mycol Res 107:957-968

Kottke I, Haug I, Setaro S, Suárez JP, Weiß M, Preußing M, Nebel M, Oberwinkler F (2008) Guilds of mycorrhizal fungi and their relation to trees, ericads, orchids and liverworts in a neotropical mountain rain forest. Basic Appl Ecol 9:13-23

Kottke I, Suárez JP, Herrera P, Cruz D, Bauer R, Haug I, Garnica S (2009) Atractiellomycetes belonging to the 'rust' lineage (Pucciniomycotina) form mycorrhizae with terrestrial and epiphytic neotropical orchids. Proc R Sc B 277:1289-1298

Krause C, Garnica S, Bauer R, Nebel M (2011) Aneuraceae (Metzgeriales) and tulasnelloid fungi (Basidiomycota) - a model for early steps in fungal symbiosis. Fung Biol 115:839-851

Kristiansen KA, Taylor DL, Kjøller R, Rasmussen HN, Rosendahl S (2001) Identification of mycorrhizal fungi from single pelotons of Dactylorhiza majalis (Orchidaceae) using single-strand conformation polymorphism and mitochondrial ribosomal large subunit DNA sequences. Molec Biol 10:2089-2093

Kron KA, Judd WS, Stevens PF, Crayn DM, Anderberg AA, Gadek PA, Quinn CJ, Luteyn JL (2002) Phylogenetic classiffication of Ericaceae: molecular and morphological evidence. Bot Rev 68:335-423

Kumar M, Yadav V, Tuteja N, Kumar Johri A (2009) Antioxidant enzyme activities in maize plants colonized with Piriformospora indica. Microbiology 155:780-790

Kumar M, Yadav V, Kumar H, Sharma R, Singh A, Tuteja N, Kumar Johri A (2011) Piriformospora indica enhances plant growth by transferring phosphate. Plant Signal Behav 6(5):723-725

Lahrmann U, Zuccaro A (2012) Opprimo ergo sum-evasion and suppression in the root endophytic fungus Piriformospora indica. MPMI 25:727-737

Lang C, Seven J, Polle A (2011) Host preferences and differential contributions of deciduous tree species shape mycorrhizal species richness in a mixed Central European forest. Mycorrhiza 21:297-308

Lee Y-C, Johnson JM, Chien C-T, Sun C, Cai D, Lou B, Oelmüller R, K-W Y (2011) Growth promotion of Chinese cabbage and Arabidopsis by Piriformospora indica is not stimulated by mycelium-synthesized auxin. MPMI 24:421-431

Li J, Yuan Z, Zhang Z (2010) The cellular robustness by genetic redundancy in budding yeast. PloS Genet 4;6(11):e1001187

Liebel HT, Bidartondo MI, Preiss K, Segreto R, Stöckel M, Rodda M, Gebauer G (2010) C and N stable isotope signatures reveal constraints to nutritional modes in orchids from the Mediterranean and Macaronesia. Am J Bot 97:903-912

Ligrone R, Duckett JG, Renzagalia KS (2012) Transitions in the evolution of early land plants: a bryological perspective. Ann Bot 109:851-871 
Lowe RGT, Howlett BJ (2012) Indifferent, affecionate, or deceitful: lifestyles and secretomes of fungi. PloS Pathog 8(3):e1002515

Ma M, Tan TK, Wong SM (2003) Identification and molecular phylogeny of Epulorhiza isolates from tropical orchids. Mycol Res 107:1041-1049

Magnus W (1900) Studien an der endotrophen Mycorrhiza von Neottia Nidus avis. Jahrb Wiss Botanik 35:205-272

Marshall R, Kombrink A, Motteram J, Loza-Reyes E, Lucas J, Hammond-Kosack KE, Thomma BP, Rudd JJ (2011) Analysis of two in planta expressed LysM effector homologs from the fungus Mycosphaerella graminicola reveals novel functional properties and varying contributions to virulence on wheat. Plant Physiol 156:756-769

Martos F, Munoz F, Pailler T, Kottke I, Gonneau C, Selosse M-A (2012) The role of epiphytism in architecture and evolutionary constraint within mycorrhizal networks of tropical orchids. Molec Ecol 21:5098-5109

Matsuda Y, Amiya A, Ito S-I (2009) Colonization patterns of mycorrhizal fungi associated with two rare orchids, Cephalanthera falcata and C. erecta. Ecol Res 24:1023-1031

Matsuda Y, Shimizu SS, Mori M, Ito S-I, Selosse M-A (2012) Seasonal and environmental changes of mycorrhizal associations and heterotrophy levels in mixotrophic Pyrola japonica (Ericaceae) growing under different light environments. Am J Bot 99:1177-1188

Matzke AJM, Weiger TM, Matzke M (2010) Ion channels at the nucleus: electrophysiology meets the genome. Molecular Plant 3:642-652

McCormick MK, Whigham DF, O’Neill J (2004) Mycorrhizal diversity in photosynthetic terrestrial orchids. New Phytol 163:425-438

McKendrick SL, Leake JR, Taylor DL, Read DJ (2002) Symbiotic germination and development of the myco-heterotrophic orchid Neottia nidus-avis in nature and its requirement for locally distributed Sebacina spp. New Phytol 154:233-247

Milligan MJ, Williams PG (1988) The mycorrhizal relationship of multinucleate rhizoctonias from non-orchids with Microtis (Orchidaceae). New Phytol 108:205-209

Molitor A, Kogel K-H (2009) Induced resistance triggered by Piriformospora indica. Plant Signal Behav 4(3):215-216

Molitor A, Zajic D, Voll LM, Pons-Kühnemann J, Samans B, Kogel K$\mathrm{H}$, Waller F (2011) Barley leaf transcriptome and metabolite analysis reveals new aspects of compatibility and Piriformospora indicamediated systemic induced resistance to powdery mildew. Molec Plant-Microbe Interact 24:1427-1439

Morris MH, Pérez-Pérez MA, Smith ME, Bledsoe CS (2008) Multiple species of ectomycorrhizal fungi are frequently detected on individual oak root tips in a tropical cloud forest. Mycorrhiza 18:375383

Moser AM, Frank JL, D'Allura JA, Southworth D (2009) Ectomycorrhizal communities of Quercus garryana are similar on serpentine and nonserpentine soils. Plant Soil 315:185-194

Motomura H, Selosse M-A, Martos F, Kagawa A, Yukawa T (2010) Mycoheterotrophy evolved from mixotrophic ancestors: evidence in Cymbidium (Orchidaceae). Ann Bot 106:573-581

Moyersoen B (2006) Pakaraimaea dipterocarpacea is ectomycorrhizal, indicating an ancient Gondwanaland origin for the ectomycorrhizal habit in Dipterocarpaceae. New Phytol 172:753-762

Moyersoen B (2012) Dispersion, an important radiation mechanism for ectomycorrhizal fungi in neotropical lowland forests? In: Sudarshana P, Nageswara-Rao M, Soneji JR (eds) Tropical forests., pp 93-116, ISBN: 978-953-51-0255-7

Mühlmann O, Peintner U (2008) Ectomycorrhiza of Kobresia myosuroides at a primary successional glacier forefront. Mycorrhiza $18: 355-362$

Mühlmann O, Bacher M, Peintner U (2008) Polygonum viviparum mycobionts on an alpine primary successional glacier forefront. Mycorrhiza 18:87-95
Müller WH, Stalpers JA, van Aelst AC, van der Krift TP, Boekhout T (1998) Field emission gun-scanning electron microscopy of septal pore caps of selected species in the Rhizoctonia s.l. complex. Mycologia 90:170-179

Nara K (2006) Pioneer dwarf willow may facilitate tree succession by providing late colonizers with compatible ectomycorrhizal fungi in a primary successional volcanic desert. New Phytol 171:187-198

Nara K, Nakaya H, Wu B, Zhou Z, Hogetsu T (2003) Underground primary succession of ectomycorrhizal fungi in a volcanic desert on Mount Fuji. New Phytol 159:743-756

Nebel M, Kreier HP, Preußing M, Weiß M, Kottke I (2004) Symbiotic fungal associations of liverworts are the possible ancestors of mycorrhizae. In: Agerer R, Piepenbring M, Blanz P (eds) Frontiers in basidiomycote mycology. IHW-Verlag, Eching, pp $339-360$

Newsham KK, Bridge PD (2010) Sebacinales are associates of the leafy liverwort Lophozia excisa in the southern maritime Antarctic. Mycorrhiza 20:307-313

Newton AC, Fitt BDL, Atkins SD, Walters DR, Daniell TJ (2010a) Pathogenesis, parasitism and mutualism in the trophic space of microbe-plant interactions. Trends Microbiol 18:365-373

Newton AC, Gravouil C, Fountaine JM (2010b) Managing the ecology of foliar pathogens: ecological tolerance in crops. Ann Appl Biol 157:343-359

Nontachaiyapoom S, Sasirat S, Manoch L (2010) Isolation and identification of Rhizoctonia-like fungi from roots of three orchid genera, Paphiopedilum, Dendrobium, and Cymbidium, collected in Chiang Rai and Chang Mai provinces in Thailand. Mycorrhiza 20:459-471

Obase K, Cha JY, Lee JK, Lee SY, Lee JH, Chun KW (2009) Ectomycorrhizal fungal communities associated with Pinus thunbergii in the eastern coastal pine forests of Korea. Mycorrhiza 20:39-49

Oberwinkler F (1963) Niedere Basidiomyceten aus Südbayern III. Die Gattung Sebacina Tul. s. 1. Ber Bayer Bot Ges 36:41-55

Oberwinkler F (1964) Intrahymeniale Heterobasidiomyceten. Fruchtkörperlose Sebacina-Sippen und ihre systematische Stellung. Nova Hedw 7:483-499

Oberwinkler F (1985) Anmerkungen zur Evolution und Systematik der Basidiomyceten. Bot Jahrb Syst 107:541-580

Oelmüller R, Peskan-Berghöfer T, Shahollari B, Trebicka A, Sherameti I, Varma A (2005) MATH domain proteins represent a novel protein family in Arabidopsis thaliana, and at least one member is modified in roots during the course of a plant-microbe interaction. Phys Plant 124:152-166

Oelmüller R, Sherameti I, Tripathi S, Varma A (2009) Piriformospora indica, a cultivable root endophyte with multiple biotechnological applications. Symbiosis 49:1-17

Okayama M, Yamato M, Yagame T, Iwase K (2012) Mycorrhizal diversity and specificity in Lecanorchis (Orchidaceae). Mycorrhiza. doi:10.1007/s00572-012-0429-z

Palmer JM, Lindner DL, Volk TJ (2008) Ectomycorrhizal characterization of an American chestnut (Castanea dentata)-dominated community in Western Wisconsin. Mycorrhiza 19:27-36

Parrent JL, James TY, Vasaitis R, Taylor AFS (2009) Friend or foe? Evolutionary history of glycoside hydrolase family 32 genes encoding for sucrolytic activity in fungi and its implications for plant-fungal symbioses. BMC Evol Biol 9:148

Peay KG, Kennedy PG, Davies SJ, Tan S, Bruns TD (2010) Potential link between plant and fungal distributions in a dipterocarp rainforest: community and phylogenetic structure of tropical ectomycorrhizal fungi across a plant and soil ecotone. New Phytol 185:529-542

Persoon CH (1796) Observationes mycologicae seu descriptiones tam novorum, quam notabilium fungorum. apud Petrum Phillippum Wolf, Lipsiae 
Peskan-Berghöfer T, Shahollari B, Giong PH, Hehl S, Markert C, Blanke V, Kost G, Varma A, Oelmüller R (2004) Association of Piriformospora indica with Arabidopsis thaliana roots represents a novel system to study beneficial plant-microbe interactions and involves early plant protein modifications in the endoplasmic reticulum and at the plasma membrane. Physiol Plant 122:465-477

Petersen LN, Ingle RA, Knight MR, Denby KJ (2009) OXI1 protein kinase is required for plant immunity against Pseudomonas syringae in Arabidopsis. J Exp Bot 60:3727-3735

Phosri C, Põlme S, Taylor AFS, Kõljalg U, Suwannasai N, Tedersoo L (2012) Diversity and community composition of ectomycorrhizal fungi in a dry deciduous dipterocarp forest in Thailand. Biodivers Conserv. doi:10.1007/s10531-012-0250-1

Plett JM (2010) Ehtylene - a key arbitrator to plant-fungal symbiotic interactions? New Phytol 185:168-171

Porras-Alfaro A, Bayman P (2011) Hidden fungi, emergent properties: endopyhtes and microbiomes. Annu Rev Phythopathol 49:291-315

Qiang X, Weiss M, Kogel K-H, Schäfer P (2012a) Piriformospora indica - a mutualistic basidiomycete with an exceptionally large plant host range. Mol Plant Pathol 5:508-518

Qiang X, Zechman B, Reitz MU, Kogel K-H, Schäfer P (2012b) The mutualistic fungus Piriformospora indica colonizes Arabidopsis roots by inducing an endoplasmic reticulum stress-triggered Caspase-dependent cell death. Plant Cell 24:794-809

Rai M, Acharya D, Singh A, Varma A (2001) Positive growth responses of the medicinal plants Spilanthes calva and Withania somnifera to inoculation by Piriformospora indica in a field trial. Mycorrhiza 11:123-128

Rasmussen HN (1995) Terrestrial orchids from seed to mycotrophic plant. University Press, Cambridge

Redecker D, Koder R, Graham LE (2000) Glomalean fungi from the Ordovician. Science 289:1920-1921

Reithmeier L (2011) Facilitation of ectomycorrhizal colonization of Picea mariana by alternate host plants above treeline. Master thesis, Dalhousie University of Halifax

Rentel MC, Lecourieux D, Ouaked F, Usher SL, Petersen L, Okamoto H, Knight H, Peck SC, Grierson CS, Hirt H, Knight MR (2004) OXI1 kinase is necessary for oxidative burst-mediated signalling in Arabidopsis. Nature 427:858-861

Reverchon F, MdP O-L, Bonilla-Rosso G, Pérez-Moreno J (2012) Structure and species composition of ectomycorrhizal fungal communities colonizing seedlings and adult trees of Pinus montezumae in Mexican neotropical forests. FEMS Microbiol Ecol 80:479-487

Richard F, Millot S, Gardes M, Selosse M-A (2005) Diversity and specificity of ectomycorrhizal fungi retrieved from an old-growth Mediterranean forest dominated by Quercus ilex. New Phytol 166:1011-1023

Richard F, Roy M, Shahin O, Sthultz C, Duchemin M, Joffre R, Selosse M-A (2011) Ectomycorrhizal communities in a Mediterranean forest ecosystem dominated by Quercus ilex: seasonal dynamics and response to drought in the surface organic horizon. Annals Forest Sci 68:57-68

Riess K (2009) Endophytische Sebacinales assoziiert mit Getreide und dessen Begleitpflanzen. Diploma thesis, University of Tübingen

Rineau F (2008) Étude des conséquences du chaulage sur la structure et le fonctionnement des communautés d'ectomycorrhizes des forêts des Vosges. Thèse pour l'obtention du titre de docteur de l'Université Henri Poincaré, Nancy

Rineau F, Garbaye J (2009) Does forest liming impact the enzymatic profiles of ectomycorrhizal communities through specialized fungal symbionts? Mycorrhiza 19:493-500

Roberts P (1993) Exidiopsis species from Devon, including the new segregate genera Ceratosebacina, Endoperplexa, Microsebacina, and Serendipita. Myc Res 97:467-478
Rodriguez R, Redman R (2008) More than 400 million years of evolution and some plants still can't make it on their own: plant stress tolerance via fungal symbiosis. J Exp Bot 59 (5):1109-1114

Roy M, Watthana S, Stier A, Richard F, Vessabutr S, Selosse M-A (2009) Two mycoheterotrophic orchids form Thailand tropical dipterocarpacean forests associate with a broad diversity of ectomycorrhizal fungi. BMC Biol 7:51

Russel J, Bulman S (2004) The liverwort Marchantia foliacea forms a specialized symbiosis with arbuscular fungi in the genus Glomus. New Phytol 165:567-579

Ryberg M, Larsson E, Molau U (2009) Ectomycorrhizal diversitiy on Dryas octopetala and Salix reticulata in an alpine cliff ecosystem. Arct Antarct Alp Res 41:506-514

Ryvarden L (1986) Tremellostereum (Tremellaceae) nov. gen. Mycotaxon 27:321-323

Satheesan J, Narayanan AK, Sakunthala M (2012) Induction of root colonization by Piriformospora indica leads to enhanced asiaticoside production in Centella asiatica. Mycorrhiza 22:195-202

Schäfer P, Khatabi B, Kogel K-H (2007) Root cell death and systemic effects of Piriformospora indica: a study on mutualism. FEMS Microbiol Lett 275:1-7

Schäfer P, Pfiffi S, Voll LM, Jajic D, Chandler PM, Waller F, Scholz U, Pons-Kühnemann J, Sonnewald S, Sonnewald U, Kogel K-H (2009) Manipulation of plant innate immunity and gibberellin as factor of compatibility in the mutualistic association of barley roots with Piriformospora indica. Plant $\mathrm{J}$ 59:461-474

Schikora A, Schenk ST, Stein E, Molitor A, Zuccaro A, Kogel K-H (2011) Bacterial N-acyl-homoserine lactone confers resistance towards biotrophic and hemibiotrophic pathogens via altered activiation of AtMPK6. Plant Physiol 157:1407-1418

Selosse M-A (2005) Are liverworts imitating mycorrhizas? New Phytol 165:345-349

Selosse M-A, Bauer R, Moyersoen B (2002a) Basal Hymenomycetes belonging to the Sebacinaceae are ectomycorrhizal on temperate deciduous trees in silva: microscopical and molecular evidence. New Phytol 155:183-195

Selosse M-A, Weiß M, Jany JL, Tillier A (2002b) Communities and populations of sebacinoid basidiomycetes associated with the achlorophyllous orchid Neottia nidus-avis (L.) L.C.M. Rich. and neighbouring tree ectomycorrhizae. Mol Ecol 11:1831-1844

Selosse M-A, Faccio A, Scappaticci G, Bonfante P (2004) Chlorophyllous and achlorophyllous specimens of Epipactis microphylla (Neottieae, Orchidaceae) are associated with ectomycorrhizal septomycetes, including truffles. Microb Ecol 47:416426

Selosse M-A, Setaro S, Glatard F, Richard F, Urcelay C, Weiß M (2007) Sebacinales are common mycorrhizal associates of Ericaceae. New Phytol 174:864-878

Selosse M-A, Dubois M-P, Alvarez N (2009) Do Sebacinales commonly associate with plant roots as endophytes? Mycol Res 113:1062-1069

Selosse M-A, Boullard B, Richardson D (2011) Noël Bernard (18741911): orchids to symbiosis in a dozen years, one century ago. Symbiosis 54:61-68

Serfling A, Wirsel SGR, Lind V, Deising HB (2007) Performance of the biocontrol fungus Piriformospora indica on wheat under greenhouse and field conditions. Phytopath 97(4):523-531

Setaro SD, Kron K (2011) Neotropical and North American Vaccinioideae (Ericaceae) share their mycorrhizal Sebacinalesan indication for concerted migration? PLoS Curr 3:RRN1227

Setaro S, Weiß M, Oberwinkler F, Kottke I (2006a) Sebacinales form ectendomycorrhizae with Cavendishia nobilis, a member of the Andean clade of Ericaceae, in the mountain rain forest of southern Ecuador. New Phytol 169:355-365 
Setaro S, Kottke I, Oberwinkler F (2006b) Anatomy and ultrastructure of mycorrhizal associations of neotropical Ericaceae. Mycol Progr $5: 243-254$

Setaro SD, Garnica S, Herrera PI, Suárez JP, Göker M (2011) A clustering optimization strategy to estimate species richness of Sebacinales in the tropical Andes based on molecular sequences from distinct DNA regions. Biodivers Conserv. doi:10.1007/ s10531-011-0205-y

Shahollari B, Vadassery J, Varma A, Oelmüller R (2007) A leucine-rich repeat protein is required for growth promotion and enhanced seed production mediated by the endophytic fungus Piriformospora indica in Arabidopsis thaliana. Plant J 50:1-13

Sharma M (2008) A functional study on the multilateral symbiosis of the fungal order Sebacinales with plant hosts and bacteria. $\mathrm{PhD}$ Thesis, Univ Gießen

Sharma M, Schmid M, Rothballer M, Hause G, Zuccaro A, Imani J, Kämpfer P, Domann E, Schäfer P, Hartmann A, Kogel K-H (2008) Detection and identification of bacteria intimately associated with fungi of the order Sebacinales. Cell Microbiol 10 (11):2235-2246

Shefferson RP, Weiß M, Kull T, Taylor L (2005) High specificity generally characterizes mycorrhizal association in rare lady's slipper orchids, genus Cypripedium. Mol Ecol 14:613-626

Sherameti I, Shahollari B, Venus Y, Altschmied L, Varma A, Oelmüller R (2005) The endophytic fungus Piriformospora indica stimulates the expression of nitrate reductase and the starch-degrading enzyme glucan-water dikinase in tobacco and Arabidopsis roots through a homeodomain transcription factor that binds to a conserved motif in their promoters. J Biol Chem 280:26241-26247

Sherameti I, Tripathi S, Varma A, Oelmüller R (2008) The root colonizing endophyte Piriformospora indica confers drought tolerance in Arabidopsis by stimulating the expression of drouhgt stress-related genes in leaves. MPMI 21:799-807

Shoresh M, Harman GE, Mastouri F (2010) Induced systemic resistance and plant responses to fungal biocontrol agents. Annu Rev Phytopathol 48:21-43

Singh LP, Singh Gill S, Tuteja N (2011) Unravelling the role of fungal symbionts in plant abiotic stress tolerance. Plant Signal Behav 6 (2): $175-191$

Sirrenberg A, Göbel C, Grond S, Czempinski N, Ratzinger A, Karlovsky P, Santos P, Feussner I, Pawlowski K (2007) Piriformospora indica affects plant growth by auxin production. Phys Plant 131:581-589

Smith SE, Read DJ (2008) Mycorrhizal symbiosis, 3rd edn. Academic, San Diego

Smith ME, Douhan GW, Rizzo DM (2007) Ectomycorrhizal community structure in a xeric Quercus woodland based on rDNA sequence analysis of sporocarps and pooled roots. New Phytol 174:847-863

Spanu PD (2012) The genomics of obligate (and nonobligate) biotrophs. Annu Rev Phytopathol 50:91-109

Spanu PD, Abbott JC, Amselem J, Burgis TA, Soanes DM, Stuber K, Loren V, van Themaat E, Brown JK, Butcher SA, Gurr SJ, Lebrun MH, Ridout CJ, Schulze-Lefert P, Talbot NJ, Ahmadinejad N, Ametz C, Barton GR, Benjdia M, Bidzinski P, Bindschedler LV, Both M, Brewer MT, Cadle-Davidson L, Cadle-Davidson MM, Collemare J, Cramer R, Frenkel O, Godfrey D, Harriman J, Hoede C, King BC, Klages S, Kleemann J, Knoll D, Koti PS, Kreplak J, Lopez-Ruiz FJ, Lu X, Maekawa T, Mahanil S, Micali C, Milgroom MG, Montana G, Noir S, O’Connell RJ, Oberhaensli S, Parlange F, Pedersen C, Quesneville H, Reinhardt R, Rott M, Sacristan S, Schmidt SM, Schon M, Skamnioti P, Sommer H, Stephens A, Takahara H, Thordal-Christensen H, Vigouroux M, Wessling R, Wicker T, Panstruga R (2010) Genome expansion and gene loss in powdery mildew fungi reveal tradeoffs in extreme parasitism. Science 330:1543-1546
Stefani FOP, Moncalvo J-M, Séguin A, Bérubé JA, Hamelin RC (2009) Impact of an 8-year-old transgenic poplar plantation on the ectomycorrhizal fungal community. Appl Environm Microbiol 75:7527-7536

Stein E, Molitor A, Kogel KH, Waller F (2008) Systemic resistance in Arabidopsis conferred by the mycorrhizal fungus Piriformospora indica requires jasmonic acid signaling and the cytoplasmic function of NPR1. Plant Cell Physiol 49:1747-1751

Suárez JP, Weiß M, Abele A, Garnica S, Oberwinkler F, Kottke I (2006) Diverse tulasnelloid fungi form mycorrhizae with epiphytic orchids in an Andean cloud forest. Mycol Res 110:1257-1270

Suárez JP, Weiß M, Abele A, Oberwinkler F, Kottke I (2008) Members of Sebacinales subgroup B form mycorrhizae with epiphytic orchids in a neotropical mountain rain forest. Mycol Progr 7:7585

Suárez JP, Weiss M, Oberwinkler F, Kottke I (2009) Epiphytic orchids in a mountain rain forest in southern Ecuador harbor groups of mycorrhiza-forming Tulasnellales and Sebacinales subgroup B (Basidiomycota). In: Pridgeon AM and Súarez P (eds) Proceedings of the Second Conference on Andean Orchids, Universidad Técnica Particular de Loja, pp 184-196

Sun C, Johnson JM, Cai D, Sherameti I, Oelmüller R, Lou B (2010) Piriformospora indica confers drought tolerance in Chinese cabbage leaves by stimulating antioxidant enzymes, the expression of drought-related genes and the plastid-localized CAS protein. J Plant Phys 167:1009-1017

Tao G, Liu ZY, Hyde KD, Liu XZ, Yu ZN (2008) Whole DNA analysis reveals novel and endophytic fungi in Bletilla ochracea (Orchidaceae). Fung Div 33:101-122

Taylor DL, McCormick MK (2007) Internal transcribed spacer primers and sequences for improved characterization of basidiomycetous orchid mycorrhizas. New Phytol 177:1020-1033

Taylor DL, Bruns TD, Szaro TM, Hodges SA (2003) Divergence in mycorrhizal specialization with Hexalectris spicata (Orchidaceae), a nonphotosynthetic desert orchid. Am J Bot 90:1168-1179

Tedersoo L (2007) Ectomycorrhizal fungi: diversity and community structure in Estonia, Seychelles and Australia. Dissertationes Biologicae Universitatis Tartuensis 127

Tedersoo L, Nara K (2010) General latitudinal gradient of biodiversity is reversed in ectomycorrhizal fungi. New Phytol 185:351-354

Tedersoo L, Kõljalg U, Hallenberg N, Larsson K-H (2003) Fine scale distribution of ectomycorrhizal fungi and roots across substrate layers including coarse woody debris in a mixed forest. New Phytol 159:153-165

Tedersoo L, Suvi T, Larsson E, Kõljalg U (2006) Diversity and community structure of ectomycorrhizal fungi in a wooded meadow. Mycol Res 110:734-748

Tedersoo L, Pellet P, Kõljalg U, Selosse M-A (2007) Parallel evolutionary paths to mycoheterotrophy in understorey Ericaceae and Orchidaceae: ecological evidence for mixotrophy in Pyroleae. Oecologia 151:206-217

Tedersoo L, Jairus T, Horton BM, Abarenkov K, Suvi T, Saar I, Kõljalg U (2008a) Strong host preference of ectomycorrhizal fungi in a Tasmanian wet sclerophyll forest as revealed by DNA barcoding and taxon-specific primers. New Phytol 180:479-490

Tedersoo L, Suvi T, Jairus T, Kõljalg U (2008b) Forest microsite effects on community composition of ectomycorrhizal fungi on seedlings of Picea abies and Betula pendula. Environ Microbiol 10:1189-1201

Tedersoo L, May TW, Smith ME (2009a) Ectomycorrhizal lifestyle in fungi: global diversity, distribution, and evolution of phylogenetic lineages. Mycorrhiza 20:217-263

Tedersoo L, Gates G, Dunk CW, Lebel T, May TW, Kõljalg U, Jairus T (2009b) Establishment of ectomycorrhizal fungal community on isolated Nothofagus cunninghamii seedlings regenerating on dead 
wood in Australian wet temperate forests: does fruit-body type matter? Mycorrhiza 19:403-416

Tedersoo L, Sadam A, Zambrano M, Valencia R, Bahram M (2010) Low diversity and high host preference of ectomycorrhizal fungi in Western Amazonia, a neotropical biodiversity hotspot. ISME J 4:465-471

Tedersoo L, Bahram M, Jairus T, Bechem E, Chinoya S, Mpumba R, Leal M, Randrianjohany E, Razafimandimbison S, Sadam A, Naadel T, Kõljalg U (2011) Spatial structure and the effects of host and soil environments on communities of ectomycorrhizal fungi in wooded savannas and rain forests of Continental Africa and Madagascar. Molec Ecol 20:3071-3080

Tesitelova T, Tesitel J, Jersakova J, Rihova G, Selosse M-A (2012) Symbiotic germination capability of four Epipactis species (Orchidaceae) is broader than expected from adult ecology. Am J Bot 99:1020-1032

Trowbridge J, Jumpponen A (2004) Fungal colonization of shrub willow roots at the forefront of a receding glacier. Mycorrhiza 14:283-293

Tulasne LRE, Tulasne C (1871) New notes on the tremellineous fungi and their analogs. J Linn Soc London Bot 13:31-42

Turnau K, Ronikier M, Unrug J (1999) Role of mycorrhizal links between plants in establishment of liverwort thalli in natural habitats. Acta Soc Botan Polon 68:63-68

Urban A, Weiß M, Bauer R (2003) Ectomycorrhizae involving sebacinoid mycobionts. Mycol Res 107:3-14

Urban A, Puschenreiter M, Strauss J, Gorfer M (2008) Diversity and structure of ectomycorrhizal and co-associated fungal communities in a serpentine soil. Mycorrhiza 18:339-354

Vadassery J, Oelmüller R (2009) Calcium signaling in pathogenic and beneficial plant microbe interactions. What can we learn from the interaction between Piriformospora indica and Arabidopsis thaliana. Plant Signal Behav 4(11):1024-1027

Vadassery J, Ritter C, Venus Y, Camehl I, Varma A, Shahollari B, Novák O, Strnad M, Ludwig-Müller J, Oelmüller R (2008) The role of auxins and cytokinins in the mutualistc interaction between Arabidopsis and Piriformospora indica. MPMI 21:13711383

Vadassery J, Ranf S, Drzewelcki C, Mithöfer A, Mazars C, Scheel D, Lee J, Oelmüller R (2009) A cell wall extract from the endophytic fungus Piriformospora indica promotes growth of Arabidopsis seedlings and induces intracellular calcium elevation in roots. Plant J 59:193-206

Van der Ent S, Van Wees SCM, Pieterse CMJ (2009) Jasmonate signaling in plant interactions with resistance-inducing beneficial microbes. Phytochem 70:1581-1588

Varma A, Verma S, Sudha SN, Bütehorn B, Franken P (1999) Piriformospora indica, a cultivable plant-growth-promoting root endopyte. Appl Environ Microbiol 65:2741-2744

Varma A, Singh A, Sudha, Sahay NS, Sharma J, Roy A, Kumari M, Rana D, Thakran S, Deka D, Bharti K, Franken P, Hurek T, Blechert O, Rexer K-H, Kost G, Hahn A, Hock B, Maier W, Walter M, Strack D, Kramer I (2001) Piriformospora indica: an axenically culturable mycorrhiza-like endosymbiotic fungus. In: Hock B (ed) The mycota, Vol IX: fungal associations. Springer, Berlin, pp 125-150

Varma A, Sherameti I, Tripathi S, Prasad R, Das A, Sharma M, Bakshi M, Johnson JM, Bhardwaj S, Arora M, Rastogi K, Agrawal A, Kharkwal AC, Talukdar S, Bagde US, Bisaria VS, Upadhyaya CP, Won PS, Chen Y, MaJ, Lou B, Adya A, Zhong L, Meghvanshi MK, Gosal SK, Srivastava RB, Johri AK, Cruz C, Oelmüller R (2012) The symbiotic fungus Piriformospora indica: Review (in press)

Vellinga EC, Wolfe BE, Pringle A (2009) Global patterns of ectomycorrhizal introductions. New Phytol 181:960-973

Verma S, Varma A, Rexer K-H, Hassel A, Kost G, Sarbhoy A, Bisen P, Bütehorn B, Franken P (1998) Piriformospora indica, gen. et sp. nov., a new root-colonizing fungus. Mycologia 90:896-903
Villareal-Ruiz L, Anderson IC, Alexander IJ (2004) Interaction between an isolate from the Hymenoscyphus ericae aggregate and roots of Pinus and Vaccinium. New Phytol 164:183-192

Vincenot L, Tedersoo L, Richard F, Horcine H, Kõljalg U, Selosse M-A (2008) Fungal associates of Pyrola rotundifolia, a mixotrophic Ericaceae, from two Estonian boreal forests. Mycorrhiza 19:15-25

Vrålstad T (2004) Are ericoid and ectomycorrhizal fungi part of a common guild? New Phytol 164:7-10

Walker JF, Parrent JL (2004) Molecular phylogenetic evidence for the mycorrhizal status of Tremellodendron (Sebacinaceae). Mem N Y Bot Gard 89:291-296

Walker JF, Miller OK Jr, Horton JL (2008) Seasonal dynamics of ectomycorrhizal fungus assemblages on oak seedlings in the southestern Appalachian Mountains. Mycorrhiza 18:123-132

Waller F, Achatz B, Baltruschat H, Fodor J, Becker K, Fischer M, Heier T, Hückelhoven R, Neumann C, von Wettstein D, Franken P, Kogel KH (2005) The endophytic fungus Piriformospora indica reprograms barley to salt-stress tolerance, disease resistance, and higher yield. Proc Natl Acad Sci USA 102:13386-13391

Waller F, Mukherjee K, Deshmukh SD, Achatz B, Sharma M, Schäfer P, Kogel K-H (2007) Systemic and local modulation of plant responses by Piriformospora indica and related Sebacinales species. J Plant Phys 165:60-70

Wang Q, Guo L-D (2010) Ectomycorrhizal community composition of Pinus tabulaeformis assessed by ITS-RFLP and ITS sequences. Botany 88:590-595

Warcup JH (1971) Specificity of mycorrhizal association in some Australian terrestrial orchids. New Phytol 70:41-46

Warcup JH (1981) The mycorrhizal relationships of Australian orchids. New Phytol 87:371-381

Warcup JH (1988) Mycorrhizal associations of isolates of Sebacina vermifera. New Phytol 110:227-231

Warcup JH (1991) The Rhizoctonia endophytes of Rhizanthella (Orchidaceae). Mycol Res 95:656-659

Warcup JH, Talbot PHB (1967) Perfect states of rhizoctonias associated with orchids I. New Phytol 66:631-641

Wei J, Agerer R (2011) Two sebacinoid ectomycorrhizae on Chinese pine. Mycorrhiza 21:105-115

Weiß M (2007) Die verborgene Welt der Sebacinales. Biologen heute $3: 18-23$

Weiß M (2010) Sebacinales: Basidiomyceten mit enormem Potential für die Mykorrhizaforschung und für Anwendungen im Pflanzenbau. J Kult 63:113-114

Weiß M, Oberwinkler F (2001) Phylogenetic relationships in Auriculariales and related groups - hypotheses derived from nuclear ribosomal DNA sequences. Mycol Res 105:403-415

Weiß M, Selosse M-A, Rexer K, Urban A, Oberwinkler F (2004) Sebacinales: a hitherto overlooked cosm of heterobasidiomycetes with a broad mycorhizal potential. Mycol Res 108:1003-1010

Weiß M, Sykorová Z, Garnica S, Riess K, Martos F, Krause C, Oberwinkler F, Bauer R, Redecker D (2011) Sebacinales everywhere: previously overlooked ubiquitous fungal endophytes. PLoS One 6(2):e16793

Wells K, Oberwinkler F (1982) Tremelloscypha gelatinosa, a species of a new family Sebacinaceae. Mycologia 74:325-331

Williams PG, Thilo E (1989) Ultrastructural evidence for the identity of some multinucleate rhizoctonias. New Phytol 112:513-518

Wright MM, Cross R, Cousens RD, May TW, McLean CB (2010) Taxonomic and functional characterisation of fungi from the Sebacina vermifera complex from common and rare orchids in the genus Caladenia. Mycorrhiza 20:375-390

Wurzburger N, Higgins BP, Hendrick RL (2011) Ericoid mycorrhizal root fungi and their multicopper oxidases from a temperate forest shrub. Ecol Evol. doi:10.1002/ece3.67

Yadav V, Kumar M, Deepak DK, Kumar H, Sharma R, Tripathi T, Tuteja N, Saxena AK, Johri AK (2010) A phosphate transporter 
from the root endophytic fungus Piriformospora indica plays a role in phosphate transport to the host plant. J Biol Chem 285:26532-26544

Yagame T (2011) Study on mycorrhizal symbioses in Orchidaceae. Japan Jour Mycol 52:11-18

Yagame T, Yamato M (2008) Isolation and identification of mycorrhizal fungi associated with Stigmatodactylus sikokianus (Maxim. ex Makino) Rauschert (Orchidaceae). Mycoscience 49:388-391

Yagame T, Orihara T, Selosse M-A, Yamato M, Iwase K (2012) Mixotrophy of Platanthera minor, an orchid associated with ectomycorrhiza-forming Ceratobasidiaceae fungi. New Phytol 193:178-187

Yukawa T, Ogura-Tsujita Y, Shefferson RP, Yokoyama J (2009) Mycorrhizal diversity in Apostasia (Orchidaceae) indicates the origin and evolution of orchid mycorrhiza. Am J Bot 96:1997-2009

Zamioudis C, Pieterse CM (2012) Modulation of host immunity by beneficial microbes. MPMI 25(2):139-150
Zhang C, Yin L, Dai S (2009) Diversity of root-associated fungal endophytes in Rhododendron fortunei in subtropical forests of China. Mycorrhiza 19:417-423

Zimmer K, Hynson NA, Gebauer G, Allen EB, Allen MF, Read DJ (2007) Wide geographical and ecological distribution of nitrogen and carbon gains from fungi in pyroloids and monotropoids (Ericaceae) and in orchids. New Phytol 175:166-175

Zuccaro A, Basiewicz M, Zurawska M, Biedenkopf D, Kogel K-H (2009) Karyotype analysis, genome organization, and stable genetic transformation of the root colonizing fungus Piriformospora indica. Fungal Genet Biol 46:543-550

Zuccaro A, Lahrmann U, Güldener U, Langen G, Pfiffi S, Biedenkopf D, Wong P, Samans B, Grimm C, Basiewicz M, Murat C, Martin F, Kogel K-H (2011) Endophytic life strategies decoded by genome and transcriptome analyses of the mutualistic root symbiont Piriformospora indica. PLoS Pathogens 7(10):e1002290. doi:10.1371/journal.ppat.1002290 